\title{
As anomalias geológicas e geofísicas localizadas ao norte de Itapororoca (PB), folha Guarabira
}

\author{
Benjamim Bley de Brito Neves ${ }^{1}$, Marta Silvia Maria Mantovani ${ }^{2}$, Cristina Ferreira de \\ Moraes $^{3}$ \& Joel Barbugiani Sigolo ${ }^{4}$
}

\begin{abstract}
Resumo Na região ao norte de Itapororoca-PB, Folha Guarabira, foram detectadas anomalias nos contextos lito-estratigráfico, geomorfológico e hidrogeológico regional. Isto se concentra numa área discriminada pelo sistema DNPM-CPRM (1974) como "vulcânicas cretácicas", sotopostas ao Grupo Barreiras. Nesta região foram definidos para o embasamento dois terrenos clássicos da Província Borborema: o S. José do Campestre (SJC, Paleoproterozóico) e Alto Pajeú (TAP, Eoneoproterozóico), respectivamente ao norte e sul do Lineamento Patos (LP). Ao longo do LP está preservada parte da cobertura do SJC, micaxistos filonitizados, amarrotados, do Grupo Seridó. Estes terrenos e cobertura estão intrudidos por plutões brasilianos que apresentam características de afiliação e isotópicas bastantes distintas entre si. Registra-se entre eles o primeiro caso de plutonismo tonalítico juvenil do Neoproterozóico da Província. Uma duricrust silicosa, com variados tipos texturais está presente na área como resquício de platôs mais elevados e dissecados, na área entre o LP e o Rio Mamanguape (alinhado por falha normal E-NE). Anomalias de F, $\mathrm{Cr}$ e Ni foram detectados neste silcrete, onde apenas raras frações de rochas ultramáficas e alcalinas foram passíveis de identificar. Além do mapeamento geológico, foram utilizadas 1000 estações gravimétricas, 584 das quais levantadas para este trabalho e adicionadas às outras do Observatório Nacional e da UFRN, de forma a cobrir toda a área de interesse, das ocorrências do silcrete e das estruturas circulares que aparecem em aerofotos nas adjacências.
\end{abstract}

Palavras-chave: anomalias geológicas, crosta silicosa, Província Borborema, Folha Guarabira.

\begin{abstract}
Geological and geophysical anomalies detected In the area north of Itapororoca-PB, Guarabira sheet. Anomalies concerning the litho-stratigraphic, geomorphic and hydrogeologic contexts were detected on the region north of Itapororoca-PB. These anomalies are concentrated in the area coined as "Cretacic volcanics" by the system DNPM-CPRM (1974), in the basement of the Barreiras Group. In this region, two classic terranes of the Borborema Province were recognized: S. José do Campestre (SJC, Paleoproterozoic) and Alto Pajeú (TAP, Eoneoproterozoic, respectively to the north and to the south of the Patos Lineamment (LP). Along LP there is preserved part of the cover rocks of the SJC, phyllonitized and drastically folded, of the Seridó Group. These terranes and cover rocks are pierced by Brasiliano plutons that display very distinct petrogenetic and isotopic characteristics. The fist case of of juvenile tonalitic plutonism of the Province is there recorded. A silicious duricrust, with many textural facies is present in the area, as relicts of previous plateau, between LP and the Mamanguape River (aligned by an E-NE normal fault). Anomalies of F, $\mathrm{Cr}$ and $\mathrm{Ni}$ were detected in this duricrust, in which some sparce fractions of ultramafic and alkaline rocks could be identified. Besides the geological mapping, a gravity survey of 548 new gravity stations was performed for the purpose in addition to 452 prexisting stations of the Observatório Nacional and of the UFRN, so covering the area of the duricrust as well as the area of some circular structures, in the surroundings.
\end{abstract}

Keywords: geological anomalies, silicious duricrust, Borborema Province, Guarabira sheet

INTRODUÇÃO Em trabalhos de reconhecimento geológico dos anos 70, o sistema CPRM-DNPM (Barbosa et al. 1974) discriminou uma área de "intrusivas cretácicas" sotopostas ao Grupo Barreiras a norte de Itapororoca, na Paraíba (a noroeste de Mamanguape). $\mathrm{Na}$ procura destas supostas intrusivas (várias tentativas no passado), foram observados uma série inusitada de anomalias no contexto geológico e geomorfológico regionais, e posteriormente, no contexto geofísico (ano- malias aeromagnéticas e gravimétricas). Na observação complementar, verificamos se tratar de uma área situada entre a extremidade oriental do Lineamento de Patos (de direção E-NE, com inúmeras evidências de reativações tardias) e a falha normal moderna que alinha o baixo curso do Rio Mamanguape. Naquela área aparecem restos de uma assembléia litológica peculiar, rica em sílica (que induziu os autores do passado à designação de "vulcânicas"), a ser discutida.

1 - Departamento de Mineralogia e Geotectônica, Instituto de Geociências, USP, São Paulo (SP), Brasil. E-mail: bbleybn@usp.br

2 - Instituto de Astronomia, Geofísica e Ciências Atmosféricas, USP, São Paulo (SP), Brasil. E-mail: marta@iag.usp.br

3 - Programa de Pós-Graduação, Instituto de Geociências, USP, São Paulo (SP), Brasil.

4 - Departamento de Geologia Sedimentar e Ambiental, Instituto de Geociências, USP, São Paulo (SP), Brasil. E-mail: jbsigolo@usp.br 
O objetivo inicial da pesquisa foi para uma tese de doutoramento de um dos autores (C. F. M), mas que não pode ser completado por razões outras. Os dados obtidos foram reunidos, complementados e são agora apresentados, porque trazem à baila uma série de informações e observações importantes (geológicas e geofísicas s. 1.) que merecem ser apresentadas à comunidade das geociências, posto que são passíveis de fomentar vários desdobramentos de pesquisa.

As peculiaridades desta área a norte de Itapororoca são de diversas ordens. Em termos litológicos, é observado um conjunto de rochas com aspecto (localmente) magmático, pseudomorfisadas por sílica, ou com intensa silicificação de rochas preexistentes (maioria praticamente inidentificáveis, em amostra de mão e ao microscópico, aspectos maciços). A este conjunto complexo chamamos informalmente e provisoriamente de Unidade (Para)- Estratigráfica Piriri do Vigário = UEPV, tentando seguir o código de nomenclatura vigente. A expressão geomorfológica desta unidade é um platô (fração residual de) elevado de até $100 \mathrm{~m}$ acima das cotas regionais do embasamento circunvizinho, peneplanizado. E em termos hidrográficos e hidrogeológicos, destaca-se a formação de muitas fontes de depressão e de contato emanando deste contexto silicoso mais elevado (cotas de até $200 \mathrm{~m}$ ), e a de um divisor de águas, que são então conduzidas para os rios Camaratuba e Mamanguape. Além disso se observa o encaixe de todos os tributários do Rio Seco (afluente do Mamanguape) que drena a área de ocorrência da UEPV.

Nessa unidade silicosa (silcrete) foram feitas observações adicionais de anomalias de F, Cr e Ni na porção mais superficial e a presença de algumas frações reliquiares (fragmentos de difícil identificação) de rochas ultramáficas e alcalinas, fantasmas silicificados de vários minerais (apatita, olivina) e a observação direta de processos adicionais desta silicificação como invasiva até de rochas gnáissicas e migmatíticas do embasamento (do Terreno Alto Pajeú). Em alguns locais a silicificação começa no embasamento e evolui para a duricrust (UEPV) sobreposta.

Consubstancia-se assim unidade mapeável em escalas $1 / 100.000$ e superiores, a que cunhamos designação provisória (UEPV), em obediência ao código vigente (Salvador 1996), e que reúne características de um complexo vulcânico-plutônico-hidrotermal-supergênico. A designação é em alusão ao seu principal e mais elevado platô (cotas até $200 \mathrm{~m}$ ), situado ao norte de Itapororoca ("Piriri do Vigário"). A constatação de evolução complexa independe do seu estudo petrológico e evolutivo, que virá em etapas, principalmente após as sondagens que estão ali em realização. por empresas de mineração, decorrência do trabalho aqui apresentado. Holoestratotipos para essa unidade estão apontadas nas secções geológicas apresentadas, após a figura 1 (esboço geológico de Guarabira), nas figuras seguintes (Fig. 2, 3, 4).

O estudo geológico desta área de interesse (cerca de 1000 estações gravimétricas consideradas), foi feito na escala $1 / 100000$, de início, nas imediações de Itapororoca e Curral de Cima. Este levantamento foi gradativamente sendo extrapolado para o mapeamento de toda Folha de Guarabira (escala 1/200.000), aqui apresentado (Fig. 1).

O estudo geofísico se concentrou no levantamento gravimétrico de semi-detalhe realizado para o presente trabalho. Entretanto, foram analisados também dados aerogeofísicos preexistentes que, embora de caráter apenas qualitativo, permitem identificar uma anomalia magnética com características $3 \mathrm{D}$ em correspondência daquela modelada por gravimetria.

Algumas ocorrências menores de litotipos similares a UEPV ocorrem (como em Minador de Baixo, em cotas de $90 \mathrm{~m}$ ). Além disso há outras cascalheiras esparsas, provavelmente resultantes do desmantelamento prévio de extensões da UEPV (como ao norte e sul de Cuité de Mamanguape), na estrada de Guarabira para Curral de Cima etc. Estas ocorrências são alvos potenciais para investigações posteriores.

A Folha Guarabira (Fig. 1) encerra partes importantes de dois terrenos tectono-estratigráficos maiores que, de acordo com Dantas et al. (1998), Brito Neves et al. (2001a) e (2001b) e de Dantas et al. (2005), que seriam fragmentos de massas supercontinentais distintas (no conceito de Howell 1995). Os terrenos foram justapostos no final do Neoproterozóico: o Terreno Rio Grande do Norte (RGN), ao norte, representado pelo seu segmento mais oriental, São José do Campestre (SJC) e o Terreno Alto Pajeú (TAP), ao sul. As observações geológicas aqui trazidas sobre a geologia e geocronologia destes terrenos são complementos das descrições prévias dos autores acima referidos.

Estes terrenos arqueano-paleoproterozóicos (SJC) e eoneoproterozóicos (TAP) estão justapostos ao longo da zona de sutura policíclica de Patos, em grande parte com geometria e marcas estruturais impostas durante a extrusão do final do Ciclo Brasiliano (Ediacarano-Cambriano). Ao longo desta zona de cisalhamento estão preservadas e deformadas rochas supracrustais da cobertura do SJC, o denominado Grupo Seridó, e alguns importantes stocks e sheets tonalíticos e granodioríticos. No meso-cenozóico, esta linha estrutural e congêneres associadas foram importantes veículos de expressão de esforços e deformação.

A pesquisa realizada foi inteiramente financiada pela FAPESP (processo 2000/13625-6), sendo consignado o agradecimento dos autores.

\section{GEOLOGIA DA FOLHA DE GUARABIRA}

Feições Morfológicas A folha em epígrafe fica na sua maior parte no do contexto dos chamados tabuleiros pliocênicos (vide revisão de Mabessone \& Cunha Silva 1991), equivalente da Superfície Sertaneja ou Pd1, de diversos autores, em diferentes análises. Esta superfície tem sua maior expressão com os depósitos correlativos o Grupo Barreiras e conexos e no embasamento as chamadas "chãs" (peneplanos, áreas de degradação erosiva maior), de cotas entre 100 e $120 \mathrm{~m}$. Para jusante dos rios regionais aparecem planícies aluviais importantes (Camaratuba, Mamanguape), prenunciadores das cotas 


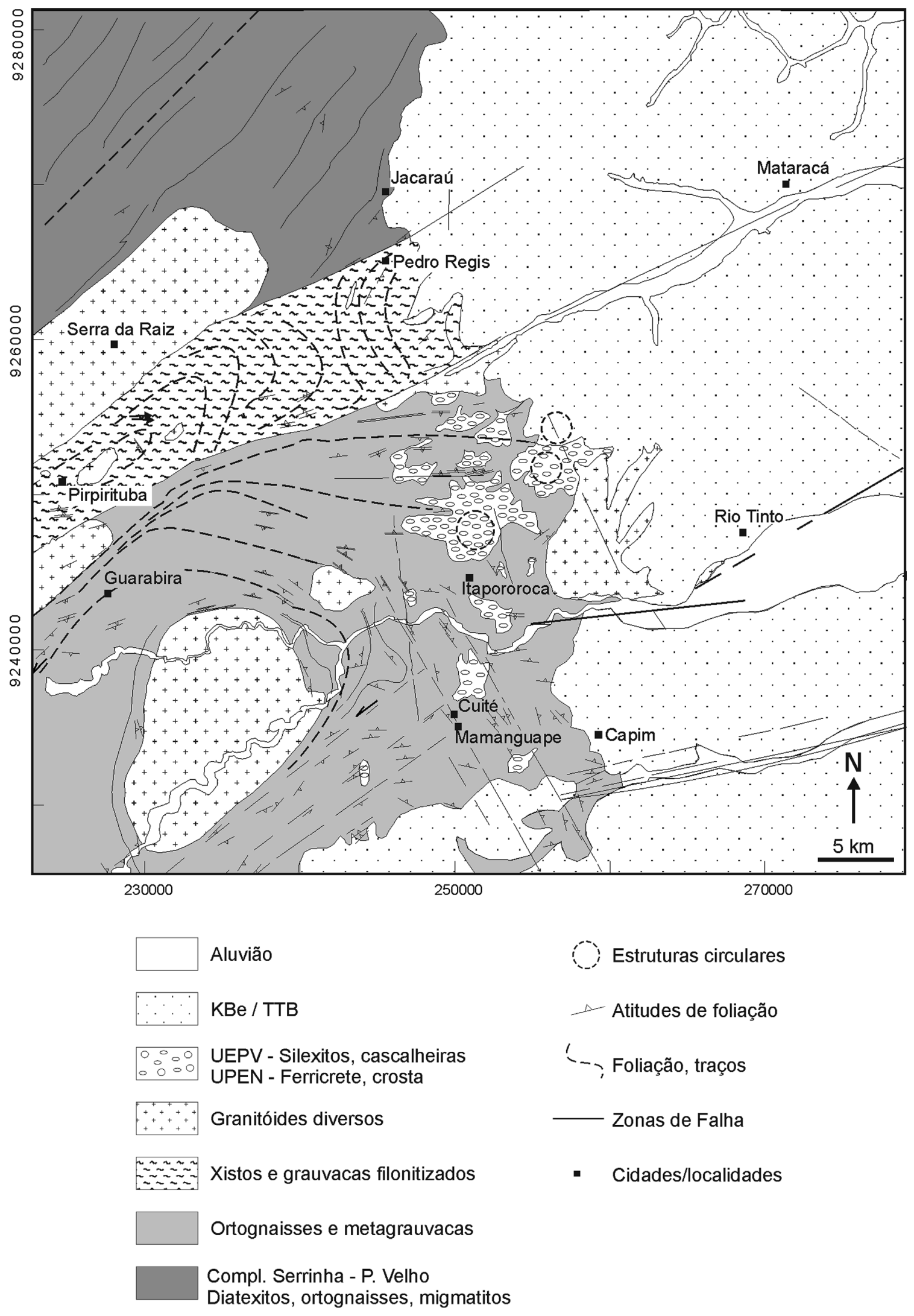

Figura 1 - Esboço geológico da Folha Guarabira.

mais baixas $(<40 \mathrm{~m})$ até a superfície costeira, chamada de Paraguassú (Ciclo Atual), ou de "Quaternária".

No tocante aos tabuleiros sedimentares, foram constatadas as presenças de vários patamares que estão bem expostos nos mapas planimétricos 1/100 .000 da SUDENE, e que jamais foram discriminados por auto- 


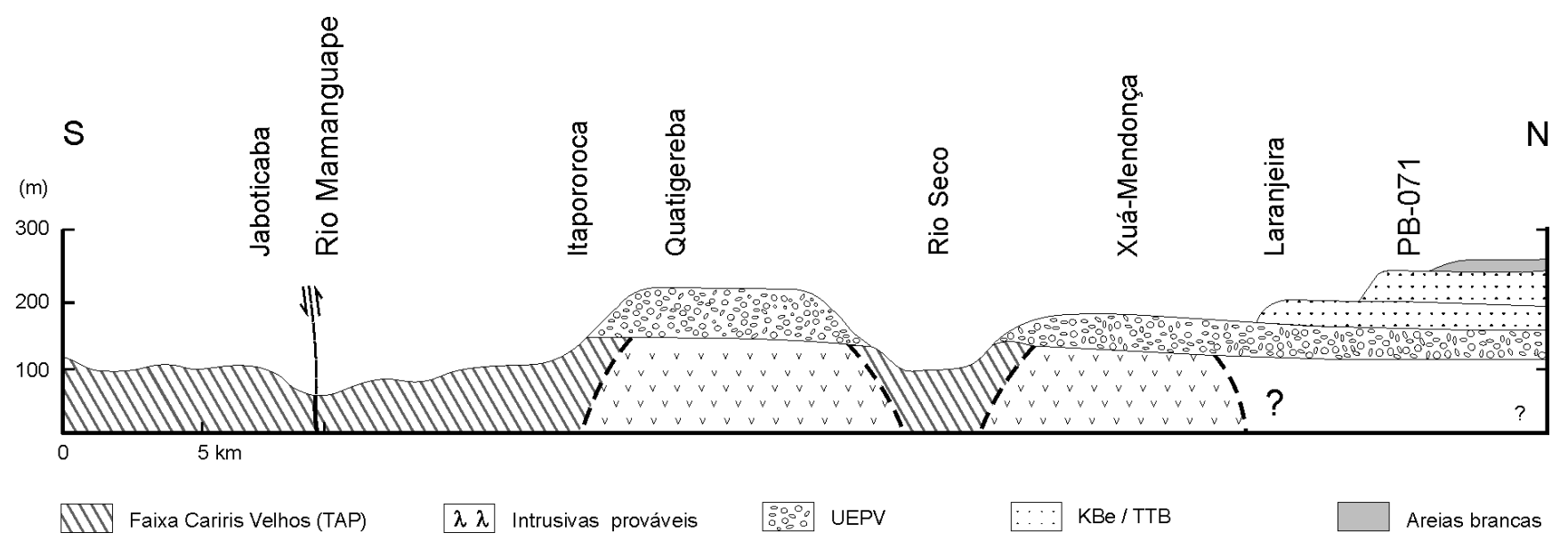

Figura 2 - Seç̧ão Geológica esquemática N-S de Jaboticaba (norte de Cuité do Mamanguape para a PB-071 (ligação da BR 101 para Jacaraú), cortando as estruturas circulares principais. considerado a secção de referência (o holoestratotipo) da Unidade Piriri do Vigário (UEPV), que aflora abundantmente em Quatigereba e Xuá-Mendonça.

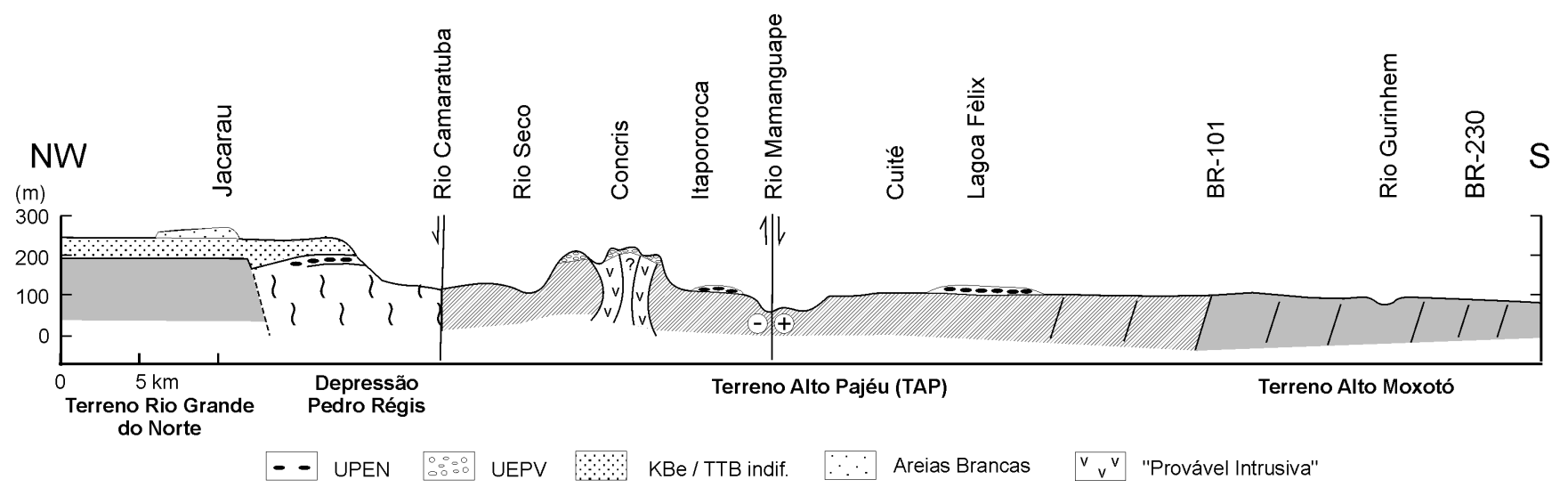

Figura 3 - Seç̧ão Geológica esquemática da rodovia BR 230 (Folha Sapé), ao sul para a cidade de Jacaraú, ao norte, passando na principal ocorrência de UEPV, em Concrís (centro da principal estrutura circular). Os três principais terrenos tectono-estratigráficos (RGN, TAP e TAM) estão representados bem como a "Depressão de Pedro Régis", a qual está alocada segundo a extremidade oriental do Lineamento Patos.

res predecessores. Estes patamares (Fig. 2, Fig 3, Fig 4) estão separados por linhas de falhas reativadas (do embasamento) que foram ocupadas preferencialmente pelos cursos d'água regionais, quase todos orientados de WSW-ENE. É possível discriminar os patamares como uma sucessão de horstes, grabens e blocos basculados consoante cotas de: (ca. $100 \mathrm{~m})$ - patamar da BR-230, mais ao sul e o patamar de Capim, este na BR-101; (ca. $200 \mathrm{~m}$ ) - patamar Palmeira-Curralinho, na fronteira das folhas Sapé-Guarabira, a SE da folha; e o patamar de Maripitanga, na BR-101 e PB-071; (ca. 250m) - patamar de Jacaraú /Alto Rio Pitanga.

Excepcionalmente, por razões ainda não devidamente esclarecidas, formou-se um patamar de ca. $650 \mathrm{~m}$, em Solânea, já na folha a oeste (Solânea, MI1133), onde as formações Serra do Martins) e Barreiras (acima do Serra do Martins) estão descritas (Moraes
Neto 1999).

Esta disposição escalonada está francamente exposta nos mapas 1/100.000 da SUDENE, reiteradas nas figuras anexas, e que realça panorama surpreendentemente diferente daquele dissertado nas usuais revisões acadêmicas sobre o tema.

A UEPV, sobreposta (e extrapolando) as áreas de anomalia geofísica, comporta uma unidade geomórfica, pois suporta a fração do platô que tangencia cotas de $200 \mathrm{~m}$ (o mesmo de Maripitanga / PB 071) e circundada por peneplanos de $<100 \mathrm{~m}$ do embasamento dissecado ("chãs" = peneplanícies, sobre rochas do TAP). Esta fração de platô divide as águas do Camaratuba e do Mamanguape, cujos tributários destes se mostram tectonicamente encaixados.

Toda a segmentação da zona dos tabuleiros e adjacências pode ser identificado como proporcionada 


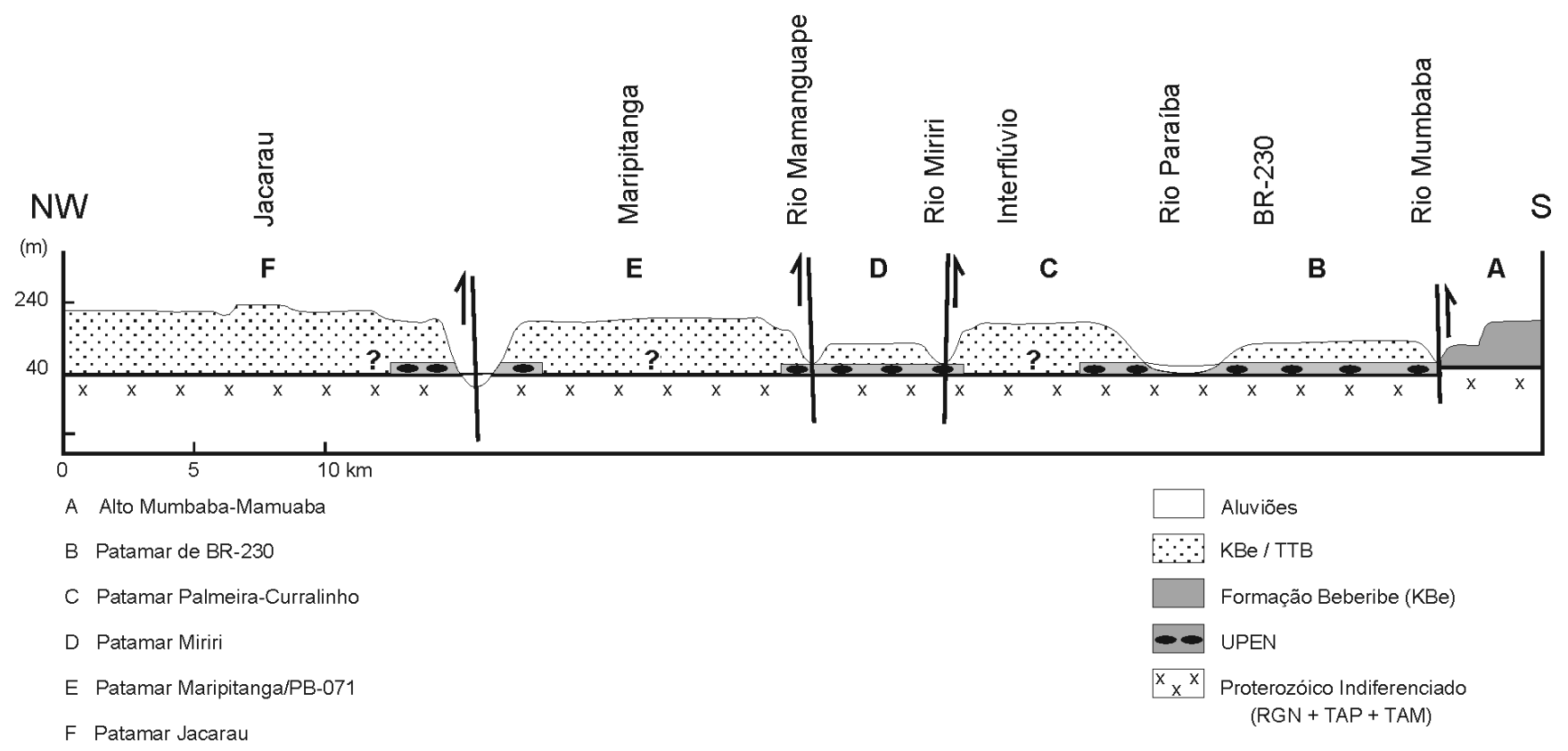

Figura 4 - Secção Geológica esquemática de sul (Folha Sapé) para N-NW (Jacaraú) procurando mostrar as diferentes frações/cotas de tabuleiros: (A) Alto Mumbaba-Mamuaba, > 200m, ao sul da BR-230 (Sub-Bacia Alhandra, folha Sapé); (B) patamar da BR-230, ca. 100m; (C) patamar/interfluvio Palmeira-Curralinho < 200m; (D) patamar de Miriri-Capim, ca. 100m; (E) patamar Maripitanga / PB 071; (F) 200-250m = patamar de Jacaraú-Alto Rio Pitanga. Nesta seç̧ão, a UPEN teve sua espessura exagerada de propósito, para destacar.

pela ação moderna das linhas de falhas Duas EstradasLagoa de Dentro, Patos, Mamanguape, Rio Miriri e Zumbi-Cuité do Mamanguape. A Lagoa de Campinas (sul de Curral de Cima) orientada ao longo do Lineamento Patos é exemplo muito didático desta situação/ obediência regional. Os topos dos tabuleiros são planos em geral, com desgastes erosivos e inclinações suaves para as vertentes e para o lado do mar, e os rios regionais se acham instalados com vertentes relativamente abruptas, com indicações de encaixe recente.

Muitos tabuleiros estão encimados (Maripitanga, Jacaraú) pelas “Areias Brancas”, unidade lito-estratigráfica informal que ocupa muitas vezes as cotas mais elevadas, sendo comum e constante o desmantelamento erosivo, facilitado pela natureza de materiais inconsolidados (em parte são elúvios e colúvios derivados da Formação Beberibe).

Esta constatação de patamares escalonados, ou de "tectônica de teclas extensionais" modernas não é só suportada pela observação morfológica, há dados de campo, deslocamentos de níveis do embasamento e de níveis basais do Barreiras, e isto tem sido ratificada no levantamento gravimétrico. A relação das estruturas do embasamento com às da cobertura é ponto de relevância nesta (Folha de Guarabira) e nas folhas adjacentes (Sapé, ao sul, S. José de Mipibú, ao norte, Solânea, a oeste etc.).

Para oeste do domínio dos tabuleiros, há predomínio da peneplanície de 100-120m (as "chãs" do embasamento). Bem mais para oeste, se inserem os primeiros contrafortes/testemunhos da Superfície Sul-
Americana (ou $\left.\mathrm{Pd}_{2}\right)$, a qual está representada (de forma rebaixada) pela maior resistência de granitos, como os de Esperança e Serra da Raiz-Serraria (cotas $350 \mathrm{~m})$.

\section{Embasamento}

O TERRENO SÃO JOSÉ DO CAMPESTRE-SJC (PARTE ORIENTAL DO RGN) No SJC, Dantas (1997) e Dantas et al. (1998) identificaram rochas de alto grau cálcio-alcalinas, geradas em orogenias acrescionárias do Paleoproterozóico (ca. $2150 \mathrm{Ma}$ ), o que foi ratificado por Brito Neves et al. (2001a e 2201b), a que designaram de Complexo Serrinha-Pedro Velho. Estas rochas metamórficas de natureza granodioríticas e trondhjemiticas, parcialmente migmatizadas, serviram para embasamento do desenvolvimento do Sistema de Dobramentos Seridó (entre 650 e $580 \mathrm{Ma}$ (Van Schmus et al. 2003) com seus depósitos de turbiditos, que vieram aportar na folha Guarabira (na chamada "Depressão de Pedro Regis", entre Pedro Regis e Pirpirituba), embutidos tectonicamente e envolvidos na tectônica cisalhante destral do lineamento de Patos.

Os nossos dados ora levantados no SJC, do ponto de vista petrográfico, estrutural, tectônico e geocronológico vem servir como adicionais àqueles já presentes na bibliografia acima mencionada (e em Dantas et al. 2004). Rochas de alto grau predominam neste segmento, biotita-hornblenda ortognaisses de composição granodiorítica a tonalítica, com intercalações anfibolíticas, localmente migmatizados. Dentro deste contexto ocorrem alguns litotipos trondhjemíticos, igual- 
mente com evidências locais de migmatização. Estas rochas apresentam foliação de alto ângulo estruturadas de NNE-SSW para NE-SW, sendo diagonalmente cortadas pelas linhas de falhas Duas Estradas-Lagoa de Dentro, paralela/complementar ao norte do Lineamento de Patos. Tratam-se de foliações de pelo menos de terceira geração, submetidas aos trendes brasilianos sobrepostos $\left(\mathrm{S}_{\mathrm{n}+3}\right)$.

Os dados isotópicos $\mathrm{Sm}-\mathrm{Nd}$ desta porção do SJC apresentam valores $\mathrm{T}_{\mathrm{DM}}$ paleoproterozóicos $(2,2 \mathrm{a}$ $2,55)$ e os valores do $\varepsilon N d\left({ }_{2150 \mathrm{Ma}}\right)$ fracamente negativos e até mesmo positivos, sugerindo a possibilidade de formação juvenil no Paleoproterozóico (Tab. 1).

Graníticas brasilianas são recorrentes nas folhas ao norte e a oeste (vide Jardim de Sá et al. 1999), aproveitando os falhamentos mais jovens da evolução brasiliana (no limite Pré-Cambriano-Fanerozóico). Na parte desta folha só o complexo granítico da Serra da Raiz-Belém (chamado de "Complexo Solânea por Guimarães et al. 2003) foi constatado. Trata-se de batólito de composição variada, mostrando tratos distintos de magmas monzograníticos, dioríticos, sienograníticos e graníticos, com muitas ocorrências de fundidos anatéticos e feições migmatíticas (e isto está também retratado nos dados isotópicos). O plutonismo é do Ciclo Brasiliano (ca. $580 \mathrm{Ma}$ ), cujos dados $\mathrm{T}_{\mathrm{DM}}$ indicam valores paleoproterozóicos e até arqueanos (2,1 a 2,6 Ga), e que preservam valores de $\varepsilon \mathrm{Nd}\left({ }_{600 \mathrm{Ma}}\right)$ fortemente negativos $(-16,0$ a - 25,0), evidenciando a participação importante de tratos crustais antigos na sua formação. Estes valores altamente negativos para plutões brasilianos são freqüentes em todo o RGN, retratando a natureza antiga de parte seus protólitos.

"GRUPO SERIDO" NO LINEAMENTO DE PATOS ("DEPRESSÃO PEDRO REGIS") E INTRUSIVAS CÁLCIO-ALCALINAS Os terrenos SJC e TAP estão justapostos consoante sutura policíclica (a cuja história muito pode ser acrescentado por nosso levantamento), o lineamento de Patos, de caráter destral, em grande parte com geometria e marcas estruturais impostas durante a extrusão do final do Ciclo Brasiliano, e que tem sido objeto de vários trabalhos prévios em seus trechos mais ocidentais. A zona ao longo do lugar geométrico desta junção (SJC com TAP), nesta folha constitui a extremidade mais oriental do lineamento, a qual foi profundamente deformada e envolveu parte da cobertura supracrustal do SJC (metapsamitos e metaritmitos argilosos, filitos e micaxistos do Grupo Seridó), de idade neoproterozóica (Van Schmus et al. 2003).

Tanto a parte mais ocidental (oeste da Folha Guarabira) do SJC, como sua borda sul-oriental apresentam frações de metassedimentos filonitizados do Grupo Seridó, como resultado de embutimento vertical ao longo de transcorrências (Jardim de Sá et al. 1999). Estes filonitos apresentam coberturas cenozóicas diversas, por toda metade oriental da folha. E todos apresentando reativações extensionais modernas, pósBarreiras.

A estruturação dos filonitos é muito complexa, sucessão de dobras de arrastos, com estilo geral de redobramento em sinformal (área de Sertãozinho-Pirpirituba). Idades U-Pb em zircão obtidas por Van Schmus et al. (op.ct.) indicam idade do Neoproterozóico mais superior (650-610 Ma) para estes metassedimentos (eventualmente meta-tufos). Os dados Sm-Nd aqui reportados, em pequeno número, indicam valores de $\mathrm{T}_{\mathrm{DM}}$ entre 1,5 e $1,4 \mathrm{Ga}$, mas com valores de $\varepsilon \mathrm{Nd}\left({ }_{600 \mathrm{Ma}}\right)$ fracamente negativos, entre $-1,5$ e $-3,7$, que sugerem algum tipo de contribuição juvenil no Neoproterozóico. Esses são valores próximos ao de granodioritos e tonalitos intrusivos a serem comentados.

Esta cobertura foi intrudida por granodioritos e tonalitos com epidoto magmático e ricos em clots anbolíticos (paralelos à foliação magmática, tipo "Conceição") os quais apresentam características isotópicas peculiares (casos de Nica, Curral de Cima etc.). A idade U-Pb em zircão indicou uma discórdia de $623 \pm 4 \mathrm{Ma}$ (situada dentro dos valores estimados para deposição, entre 650 e 610 Ma, Van Schmus et al. op. cit.). Os valores de idade $\mathrm{T}_{\mathrm{DM}}$ para estas rochas intrusivas são em geral mais jovens que $1,3 \mathrm{Ga}$, com valores de $\varepsilon \mathrm{Nd}$ Ma) próximos a zero (entre $+2,0$ e $-3,56$ ), o que consubstancia as primeiras ocorrências de plutonismo juvenil neoproterozóico em toda a Província Borborema.

Esta zona marcada pelos afluentes da margem esquerda do Rio Camaratuba foi estruturalmente deprimida no Neógeno, formando a "Depressão de Pedro Régis", já mencionada, estando afetado consideravelmente o tabuleiro Barreiras/Beberibe.

TERRENO ALTO PAJEÚ- TAP O Terreno Alto Pajeú - TAP (vide Santos \& Medeiros 1999 e Brito Neves et al. (2001a e 2001b) ocupa toda porção sul e centrooriental da folha, em grande parte acobertado por sedimentos fanerozóicos Beberibe, Barreiras, UEPV, cascalheiras, aluviões). Este terreno, na sua porção mais oriental reitera as características composicionais descritas por Brito Neves et al. (acima citado) e por Santos et al. (2002), para todo o conjunto, com o predomínio de ortognaisses bandados e migmatíticos ("Cariris Velhos") e metagrauvacas a duas micas (Complexo "São Caetano"), com algumas intercalações meta-vulcânicas, félsicas principalmente.

Como peculiaridade, nesta parte mais oriental, este terreno apresenta freqüentes processos de migmatização, e isotopicamente mostra evidências de heranças do embasamento paleoproterozóico. Adicionalmente, do ponto de vista estrutural registra-se quadro marcante de zonas de cisalhamento, diferencial importante do overprint Brasiliano. E esta tectônica sobreposta ao Cariris Velhos, transferiu legados para o quadro cenozóico.

$\mathrm{Na}$ escala do mapeamento não foram discriminados os ortognaisses (granodioríticos, graníticos/ "Cariris Velhos") das rochas meta-psamíticas aluminosas com vulcânicas intercaladas (gnaisses e micaxistos a duas micas/ "São Caetano"), nem discriminados os domínios da migmatização. Em alguns pontos, sem o devido respaldo geocronológico, fica difícil distinguir 
se os afloramentos migmatíticos são do Cariris Velhos ou do seu embasamento (Terreno alto Moxotó $=$ TAM), cujo domínio de ocorrência ostensiva é bem mais ao sul, na folha de Sapé.

Destaca-se neste contexto de ortognaisses do TAP uma zona de biotita-muscovita granitos e granodioritos, de textura milonítica a protomilonítica que baliza toda a porção norte do TAP, de Soledade até Guarabira, passando por Alagoa Nova, conhecido pela alcunha de "Rachinha" (perlonga as zonas de cisalhamento de Campina Grande e Matinhas, Archanjo \& Fetter 2004), muito utilizada como pedra de revestimento. $\mathrm{O}$ aspecto geral é de uma faixa de granitos colisionais eoneoproterozóicos submetidos drasticamente ao cisalhamento simples.

Alguns granitos brasilianos, a serem discutidos (e.g. Santa Lúcia, Mamanguape) mostram claramente a importância de protólitos paleoproterozóicos e evidenciam as condições mais elevadas do grau de metamorfismo, além de indicar a presença possível de tratos de embasamento ocorrendo na folha em epígrafe (injunções locais da tectônica e/ou da erosão), sem que tenha sido possível cartografá-los adequadamente.

Do ponto de vista estrutural, destaca-se primeiramente o feixe "rabo de cavalo" (horse-tail) advindo do splay out oriental da zona de cisalhamento sinistral Galante-Serra Redonda-Guarabira (que se origina bem a oeste da Paraíba, vide Santos et al. 2002), o qual forma notável leque aberto para leste e que vem se justapor de forma adventícia lateralmente ao Lineamento de Patos (para o norte) e circunscrever (para o sul) o batólito granítico de Lourenço.

Outras zonas de cisalhamento importantes são aquelas de Mulungú-Violeta (SW-NE, caráter sinistral), com mais de $2 \mathrm{~km}$ de largura, sub-paralela ao trend regional de ortognaisses (Cariris Velhos) e metagrauvacas (S. Caetano), e aquela que lhe é posterior no tempo, a de Pacatuba-Zumbi-Cuité do Mamanguape e que a segmenta em dois ramos, com direção NNW (azimute 350). Advinda do sul, da folha de Sapé, a leste do falhamento de Pacatuba-Cuité chega até as proximidades de Itapororoca, e desloca a zona de falha de VioletaMulungú por ca. $10 \mathrm{~km}$ (vide esboço de mapa geológico, Fig. 1).

Algumas determinações U-Pb prévias (folhas de Sapé e Guarabira, Brito Neves et al. (2001 a e 2001 b) pelo método $\mathrm{U}-\mathrm{Pb}$ reiteram a idade de ca. $960 \mathrm{Ma}$ para os metamorfitos do TAP. As determinações Sm$\mathrm{Nd}$ realizadas nos ortognaisses do TAP mostram um quadro algo distinto daquele das folhas a oeste (usualmente $<1,8 \mathrm{Ga}$ ), com valores $\mathrm{T}_{\mathrm{DM}}$ relativamente elevados, entre 1,7 e $2,4 \mathrm{Ga}$, e valores de $\varepsilon \mathrm{Nd}\left({ }_{960 \mathrm{Ma}}\right) \mathrm{mo}-$ derados a fortemente negativos $(-6,0$ até $-15,0)$. Esta constatação reiterada de participação de componentes de residência crustal mais antiga já estava esboçado na análise lito-estrutural acima efetuada, e será reforçada no trato dos dados isotópicos das metagrauvacas e das plutônicas intrusivas no TAP.

No tocante às metagrauvacas ("S. Caetano"), com o pequeno número de análises, foram ratificadas conclusões preexistentes (Brito Neves et al. 2001a e b). Foram encontrados três valores de $\mathrm{T}_{\mathrm{DM}}$ do Meosproteorozóico, com valores de $\varepsilon \mathrm{Nd}\left({ }_{960 \mathrm{Ma}}\right)$ positivos (2 casos) e um caso de valor negativo (muito próximo de zero, vide Tab. 1). Isto é interpretado como evidência de contribuição juvenil, eoneoproterozóica. Devem ser acrescentados também valores obtidos de amostras coletadas mais a sudoeste (folha de Sapé), próximo a Mulungú, onde os valores de $\varepsilon N d\left({ }_{960 \mathrm{Ma}}\right)$ são significativamente negativos $(-11,0$ a $-13,0)$, indicando a co-participação de tratos crustais antigos na formação desses metamorfitos.

ROCHAS GRANITICAS DO TERRENO ALTO PAJEÚ-TAP (a) O corpo granítico de Esperança-Pocinhos apresenta posição inter-terrenos (entre RGN e TAP) e chega ao norte de Guarabira (Serra da Jurema), apertado entre o LP e o splay out da falha Galante-Serra Redonda (sinistral). Predominam rochas graníticas porfiríticas na maior parte de sua exposição, na folha Campina Grande, mais a oeste. Bastante deformado, entre dois conjuntos cisalhantes, esta porção deste corpo foi tratado indevidamente como "ortognaisses" (pretensas rochas de embasamento) em vários mapeamentos regionais anteriores. Predominam rochas tonalíticas, sienograniticas e graníticas com texturas porfiríticas (objetos de trabalho de Archanjo \& Fetter (2004).

Para este corpo de dimensões batolíticas preexistem determinações U-Pb de Guimarães et al. (inédita), de ca 581 Ma e de Archanjo \& Fetter (2004) de $592 \pm 5 \mathrm{Ma}$, ou seja idade da parte média do Ediacarano, compativel com alguns dados $\mathrm{Rb}-\mathrm{Sr}$ convencionais obtidos por Brito Neves et al. (inédito, ca $570 \mathrm{Ma}$ ), ao norte de Guarabira.

Os dados Sm-Nd obtidos neste batólito, neste trabalho e naquele Archanjo \& Fetter (2004) são bastante coerentes, com valores de $\mathrm{T}_{\mathrm{DM}}$ entre 1,3 e $2,0 \mathrm{Ga}$ e valores $\varepsilon N d\left(_{580 \mathrm{Ma}}\right)$ negativos entre $-5,0 \mathrm{e}-16,0$, mostrando que houve participação moderada a elevada de materiais crustais preexistentes. Estes valores são mais próximos em geral daqueles do TAP (embora sejam distintos daqueles dos granitos de Lourenço e Mamanguape, abaixo descritos), e são significativamente diferentes daqueles dos granitóides situados no SJC.

(b) O Batólito de Lourenço ocorre a sudoeste da folha, "ajustado" tectonicamente entre (ao sul de) o horse tail da falha de Galante-Guarabira e a zona de cisalhamento de Violeta-Mulungu, tendo por característica morfológica ser área rebaixada ("chã" de cotas $<100 \mathrm{~m}$ ), recoberta por extensa cascalheira. Apresenta forma de pêra e área pouco superior a $100 \mathrm{~km}^{2}$, com composição monzodiorítica de alto potássio, textura ora grosseira a porfirítica, ora equigranular, que localmente exibe foliação magmática, com enclaves tonalíticos e quartzo-dioríticos alinhados com a foliação magmática. A foliação das encaixantes circundantes deste corpo mostra mergulhos fortes centripetais, conferindo-lhe pois características de unidade sintectônica. Além disto, na periferia do corpo aparecem bandas migmatíticas alternando com anéis graníticos (aspecto "estromatíti- 
Tabela 1 - Dados analiticos das determinações Sm-Nd nas rochas do embasamento.

\begin{tabular}{|c|c|c|c|c|c|c|c|c|c|}
\hline & \multirow[t]{2}{*}{ SPS } & \multirow[t]{2}{*}{ No Campo } & \multicolumn{2}{|c|}{ coordenadas } & \multirow{2}{*}{$\begin{array}{l}\text { Material } \\
\text { (Rocha) }\end{array}$} & \multirow{2}{*}{$\begin{array}{c}\mathrm{Sm} \\
(\mathrm{ppm})\end{array}$} & \multirow{2}{*}{$\begin{array}{c}\mathrm{Nd} \\
(\mathrm{ppm})\end{array}$} & \multirow{2}{*}{${ }^{147} \mathrm{Sm} /$} & \multirow[t]{2}{*}{ Erro } \\
\hline & & & latitude & longitute & & & & & \\
\hline \multirow[b]{6}{*}{ A } & 1277 & SCB-GN-SLG & 9235000 & 191000 & $\mathrm{gn} / \mathrm{rt}$ & 7,15 & 40,96 & 0,1056 & 0,0004 \\
\hline & 1819 & SCB GN BRA & 9273500 & 232000 & Ortognaisse/RT & 4,32 & 30,81 & 0,0847 & 0,0003 \\
\hline & 2572 & RN GR SR 22 & 9267129 & 227707 & RT/OrtoGnaisse & 3,60 & 27,88 & 0,0780 & 0,0003 \\
\hline & 2931 & MSJC CNB & 9269280 & 243768 & RT/Ortognaisse & 4,32 & 26,44 & 0,0988 & 0,0003 \\
\hline & 2932 & MSJC-N BVI & 9274887 & 240137 & RT/Ortognaisse & 4,48 & 30,43 & 0,0890 & 0,0003 \\
\hline & 2933 & MSJC UMARI & 9274887 & 259613 & RT/Ortognaisse & 6,42 & 42,03 & 0,0923 & 0,0003 \\
\hline \multirow{6}{*}{ B } & 1075 & SCB-GR-WPi & 9352000 & 220000 & Granitica/RT & 10,01 & 69,28 & 0,0873 & 0,0003 \\
\hline & 1807 & SCB GR S.RAIZ & 9260276 & 230436 & Granito/RT & 5,40 & 26,50 & 0,1233 & 0,0004 \\
\hline & 1869 & SCB GR S.RAIZ & 9260276 & 230436 & Granito/RT & 5,41 & 26,36 & 0,1241 & 0,0004 \\
\hline & 1076 & SCB-GR-RN & 9256000 & 220000 & Granitica/RT & 14,81 & 111,72 & 0,0802 & 0,0003 \\
\hline & 2572 & RN GR MSB & 9267129 & 227707 & RT/OrtoGnaisse & 3,60 & 27,88 & 0,0780 & 0,0003 \\
\hline & 1813 & SCB-Gr-MSB A16 & 9295000 & 178000 & Granito/RT & 7,46 & 44,45 & 0,1015 & 0,0004 \\
\hline \multirow[b]{2}{*}{$\mathrm{C}$} & 1461 & SCB MGV-PIR & 9249000 & 225000 & metagr/rt & 6,28 & 29,59 & 0,1284 & 0,0004 \\
\hline & 1812 & SCB-BX-MSB & 9240000 & 192000 & M.B.Xisto/RT & 3,72 & 16,49 & 0,1363 & 0,0005 \\
\hline \multirow[b]{3}{*}{$\mathrm{D}$} & 2564 & LP-GR-34 & 9256813 & 252214 & RT/Granitóide & 4,49 & 24,01 & 0,1129 & 0,0004 \\
\hline & 1808 & SCB-GR-NICA & 9251510 & 227062 & Granito/RT & 9,44 & 49,25 & 0,1159 & 0,0004 \\
\hline & 3523 & SCB-TON-CC & 9257000 & 248110 & Tonalito & 4,29 & 23,22 & 0,1118 & 0,0004 \\
\hline \multirow{12}{*}{$\mathrm{E}$} & 2745 & AP-CV-GN-45 & 9244547 & 245983 & RT/OrtoGnaisse & 7,90 & 39,39 & 0,1213 & 0,0004 \\
\hline & 2746 & AP CV 7 dale & 9243325 & 249930 & RT/OrtoGnaisse & 16,45 & 78,33 & 0,1270 & 0,0005 \\
\hline & 2911 & AP-AR-GN & 9242300 & 246500 & RT/Ortognaisse & 7,14 & 30,67 & 0,1408 & 0,0005 \\
\hline & 2912 & AP-AR-FEL & 9242300 & 246500 & RT/Felsito & 3,97 & 20,03 & 0,1198 & 0,0004 \\
\hline & 2747 & AP-CV-49 & 9250786 & 249648 & RT/OrtoGnaisse & 2,03 & 4,36 & 0,2819 & 0,0010 \\
\hline & 1588 & SCB--MI-MIR & 9231987 & 259300 & MIGMATITO/rt & 3,48 & 18,41 & 0,1143 & 0,0004 \\
\hline & 1804 & SCB-GN-ZB1 & 9227449 & 257723 & Ortognaisse/RT & 13,82 & 83,87 & 0,0997 & 0,0003 \\
\hline & 1820 & SCB-GN-SMB & 9225000 & 256000 & Ortognaisse/RT & 22,59 & 43,88 & $31 \%$ & 0,0012 \\
\hline & 2934 & SCB-GN-CMG & 9235425 & 251827 & RT/Ortognaisse & 9,93 & 61,11 & 0,0983 & 0,0003 \\
\hline & 3046 & SCB-GAM & 9228609 & 255973 & RT/Ortogns Gnd & 5,48 & 29,19 & 0,1134 & 0,0004 \\
\hline & 3047 & SCB-LFX & 9230463 & 250162 & RT/Ortogns Grn & 4,06 & 26,17 & 0,0937 & 0,0003 \\
\hline & 3118 & SCB-GN-PCT & 9221000 & 259000 & RT/Ortognaisse & 8,91 & 55,70 & 0,0966 & 0,0003 \\
\hline \multirow[b]{5}{*}{$\mathrm{F}$} & 2562 & AP Mgv 1 (Rio & 9241980 & 2641985 & RT/MetaGrauvaca & 4,92 & 23,56 & 0,1263 & 0,0013 \\
\hline & 1462 & SCB MGV-AG & 9222000 & 208050 & metagr/rt & 6,00 & 28,26 & 0,1283 & 0,0004 \\
\hline & 1466 & SCB-GN-S-9 & 9242000 & 197000 & biotgn/rt & 5,38 & 39,18 & 0,0830 & 0,0003 \\
\hline & 933 & SCB-GN-MUL & 9222000 & 228000 & bt-gnaisse/RT & 6,25 & 31,89 & 0,1185 & 0,0004 \\
\hline & 2563 & AP-MGV 16 & 9241489 & 255196 & RT/MetaGrauvaca & 4,43 & 23,44 & 0,1142 & 0,0004 \\
\hline \multirow[b]{2}{*}{ G } & 2569 & AP-GR-ESP 18 & 9247260 & 226640 & RT/Granito & 18,63 & 117,43 & 0,0959 & 0,0003 \\
\hline & 1279 & SCB- Gn-USM & 9236000 & 209000 & $\operatorname{ortogn} / \mathrm{rt}$ & 9,36 & 48,21 & 0,1173 & 0,0004 \\
\hline \multirow[b]{3}{*}{$\mathrm{H}$} & 2567 & AP-GR-AR-14 & 9241590 & 233710 & RT/Granito & 6,08 & 36,68 & 0,1003 & 0,0004 \\
\hline & 1589 & SCB-GR-SLO & 9231000 & 230000 & GRANITICA/rt & 13,77 & 83,12 & 0,1002 & 0,0003 \\
\hline & 2865 & AP-GR-70 & 9230281 & 233274 & RT/Granito & 7,07 & 48,15 & 0,0888 & 0,0003 \\
\hline \multirow[b]{2}{*}{ I } & 2571 & AP-SL-10 & 9243657 & 243081 & RT/Granitóide & 6,04 & 26,05 & 0,1402 & 0,0005 \\
\hline & 1278 & SCB-GR-CSL & 9244000 & 242000 & $\mathrm{gr} / \mathrm{rt}$ & 6,55 & 27,73 & 0,1428 & 0,0005 \\
\hline \multirow[b]{3}{*}{$\mathrm{J}$} & 2565 & AP-GR-M1 & 9245136 & 266607 & RT/Granito & 4,75 & 21,36 & 0,1346 & 0,0005 \\
\hline & 2566 & AP-GR-M3 & 9245322 & 259613 & RT/Granito & 15,87 & 73,92 & 0,1299 & 0,0004 \\
\hline & 2570 & AP-GR-ALA 27 & 9248568 & 257736 & RT/Granito & 2,71 & 8,55 & 0,1916 & 0,0007 \\
\hline & & $\mathrm{B}=$ Complexo Solâ & & Gr. Seridó & $\mathrm{D}=\mathrm{T}$ & Cima & & P/gnaiss & \\
\hline
\end{tabular}


Tabela 1 - Continuidade

\begin{tabular}{|c|c|c|c|c|c|c|c|c|c|c|}
\hline & SPS & No Campo & $\begin{array}{l}{ }^{143} \mathrm{Nd} / \\
{ }^{144} \mathrm{Nd}\end{array}$ & Erro & $\mathrm{fSm} / \mathrm{Nd}$ & $\begin{array}{c}\text { TDePaolo } \\
\text { (Ma) }\end{array}$ & Erro & $\mathrm{e}(0)$ & $\begin{array}{c}\mathrm{T}_{1} \\
(\mathrm{Ma})\end{array}$ & $\varepsilon_{(\mathrm{T} 1)}$ \\
\hline \multirow[b]{6}{*}{ A } & 1277 & SCB-GN-SLG & 0,51124 & 0,000007 & $-0,46$ & 2552,5 & 11,9 & $-27,19$ & 2150,0 & $-2,22$ \\
\hline & 1819 & SCB GN BRA & 0,51108 & 0,000011 & $-0,57$ & 2333,9 & 13,1 & $-30,49$ & 2150,0 & 0,22 \\
\hline & 2572 & RN GR SR 22 & 0,51091 & 0,000009 & $-0,60$ & 2402,6 & 10,5 & $-33,65$ & 2150,0 & $-1,10$ \\
\hline & 2931 & MSJC CNB & 0,511123 & 0,000011 & $-0,50$ & 2562,5 & 15,2 & $-29,56$ & 2150,0 & $-2,71$ \\
\hline & 2932 & MSJC-N BVI & 0,511049 & 0,000013 & $-0,55$ & 2447,5 & 15,8 & $-31,00$ & 2150,0 & $-1,45$ \\
\hline & 2933 & MSJC UMARI & 0,511225 & 0,000012 & $-0,53$ & 2290,3 & 15,1 & $-27,57$ & 2150,0 & 1,06 \\
\hline \multirow{6}{*}{ B } & 1075 & SCB-GR-WPi & 0,51121 & 0,000039 & $-0,56$ & 2219,0 & 44,5 & $-27,89$ & 580,0 & $-19,80$ \\
\hline & 1807 & SCB GR S.RAIZ & 0,51154 & 0,000006 & $-0,37$ & 2552,9 & 14,0 & $-21,44$ & 600,0 & $-15,82$ \\
\hline & 1869 & SCB GR S.RAIZ & 0,51149 & 0,000016 & $-0,37$ & 2665,8 & 27,2 & $-22,41$ & 600,0 & $-16,86$ \\
\hline & 1076 & SCB-GR-RN & 0,5112 & 0,000011 & $-0,59$ & 2109,7 & 12,5 & $-28,09$ & 600,0 & $-19,17$ \\
\hline & 2572 & RN GR MSB & 0,51091 & 0,000009 & $-0,60$ & 2402,6 & 10,5 & $-33,65$ & 600,0 & $-24,57$ \\
\hline & 1813 & SCB-Gr-MSB A16 & 0,51122 & 0,000013 & $-0,48$ & 2483,2 & 17,9 & $-27,58$ & 600,0 & $-20,29$ \\
\hline \multirow[b]{2}{*}{$\mathrm{C}$} & 1461 & SCB MGV-PIR & 0,512180 & 0,000016 & $-0,35$ & 1538,1 & 27,1 & $-8,93$ & 600,0 & $-3,70$ \\
\hline & 1812 & SCB-BX-MSB & 0,512322 & 0,000013 & $-0,31$ & 1416,7 & 24,4 & $-6,16$ & 600,0 & $-1,54$ \\
\hline \multirow[b]{3}{*}{$\mathrm{D}$} & 2564 & LP-GR-34 & 0,51241 & 0,000024 & $-0,43$ & 959,8 & 33,8 & $-4,41$ & 550,0 & 1,47 \\
\hline & 1808 & SCB-GR-NICA & 0,51217 & 0,000011 & $-0,41$ & 1366,4 & 16,6 & $-9,23$ & 550,0 & $-3,56$ \\
\hline & 3523 & SCB-TON-CC & 0,51218 & 0,000009 & $-0,43$ & 1300,0 & & $-8,96$ & 630,0 & \\
\hline \multirow{12}{*}{$\mathrm{E}$} & 2745 & AP-CV-GN-45 & 0,511725 & 0,000016 & $-0,38$ & 2177,7 & 25,8 & $-17,81$ & 960,0 & $-8,57$ \\
\hline & 2746 & AP CV 7 dale & 0,512047 & 0,000016 & $-0,35$ & 1749,1 & 27,2 & $-11,54$ & 960,0 & $-3,00$ \\
\hline & 2911 & AP-AR-GN & 0,512398 & 0,000012 & $-0,28$ & 1345,6 & 24,0 & $-4,68$ & 960,0 & 2,16 \\
\hline & 2912 & AP-AR-FEL & 0,512193 & 0,000011 & $-0,39$ & 1377,8 & 17,4 & $-8,68$ & 960,0 & 0,74 \\
\hline & 2747 & AP-CV-49 & 0,512815 & 0,000015 & 0,43 & $-30845,3$ & 40,3 & 3,45 & 960,0 & $-6,99$ \\
\hline & 1588 & SCB--MI-MIR & 0,51152 & 0,000012 & $-0,42$ & 2347,9 & 18,9 & $-21,85$ & 960,0 & $-11,76$ \\
\hline & 1804 & SCB-GN-ZB1 & 0,51146 & 0,000013 & $-0,49$ & 2116,9 & 17,3 & $-22,94$ & 960,0 & $-11,06$ \\
\hline & 1820 & SCB-GN-SMB & 0,51162 & 0,000008 & 0,58 & --- & --- & $-19,94$ & 960,0 & $-33,97$ \\
\hline & 2934 & SCB-GN-CMG & 0,5117 & 0,00001 & $-0,50$ & 1775,3 & 13,19 & $-18,33$ & 960,0 & $-6,28$ \\
\hline & 3046 & SCB-GAM & 0,5118 & 0,00001 & $-0,42$ & 1890,8 & 15,47 & $-16,37$ & 960,0 & $-6,17$ \\
\hline & 3047 & SCB-LFX & 0,5112 & 0,000001 & $-0,52$ & 2356,1 & 5,641 & $-28,14$ & 960,0 & $-15,53$ \\
\hline & 3118 & SCB-GN-PCT & 0,511546 & 0,000011 & $-0,51$ & 1948,8 & 14,3 & $-21,29$ & 2000,0 & 4,25 \\
\hline \multirow[b]{5}{*}{$\mathrm{F}$} & 2562 & AP Mgv 1 (Rio & 0,5123 & 0,000025 & $-0,36$ & 1287,1 & 43,8 & $-6,52$ & 960,0 & 2,11 \\
\hline & 1462 & SCB MGV-AG & 0,51225 & 0,000025 & $-0,35$ & 1409,8 & 41,4 & $-7,53$ & 960,0 & 0,84 \\
\hline & 1466 & SCB-GN-S-9 & 0,51134 & 0,000017 & $-0,58$ & 1982,9 & 19,1 & $-25,24$ & 960,0 & $-11,32$ \\
\hline & 933 & SCB-GN-MUL & 0,51146 & 0,000029 & $-0,40$ & 2556,1 & 44,0 & $-23,04$ & 960,0 & $-13,46$ \\
\hline & 2563 & AP-MGV 16 & 0,51204 & 0,000022 & $-0,42$ & 1542,2 & 31,8 & $-11,76$ & 960,0 & $-1,66$ \\
\hline \multirow{2}{*}{ G } & 2569 & AP-GR-ESP 18 & 0,51143 & 0,000014 & $-0,51$ & 2087,0 & 17,8 & $-23,51$ & 580,0 & $-16,05$ \\
\hline & 1279 & SCB- Gn-USM & 0,51213 & 0,000025 & $-0,40$ & 1446,8 & 36,9 & $-9,97$ & 580,0 & $-4,10$ \\
\hline \multirow[b]{3}{*}{$\mathrm{H}$} & 2567 & AP-GR-AR-14 & 0,51166 & 0,000012 & $-0,49$ & 1860,8 & 16,2 & $-19,12$ & 600,0 & $-11,74$ \\
\hline & 1589 & SCB-GR-SLO & 0,51154 & 0,000009 & $-0,49$ & 2022,3 & 12,5 & $-21,46$ & 600,0 & $-14,07$ \\
\hline & 2865 & AP-GR-70 & 0,51149 & 0,000014 & $-0,55$ & 1891,0 & 16,6 & $-22,32$ & 600,0 & $-14,06$ \\
\hline \multirow[b]{2}{*}{ I } & 2571 & AP-SL-10 & 0,51156 & 0,000014 & $-0,29$ & 3125,2 & 31,3 & $-20,95$ & 600,0 & $-16,63$ \\
\hline & 1278 & SCB-GR-CSL & 0,51161 & 0,00001 & $-0,27$ & 3146,1 & 26,0 & $-20,11$ & 600,0 & $-15,98$ \\
\hline \multirow[b]{3}{*}{$\mathrm{J}$} & 2565 & AP-GR-M1 & 0,51164 & 0,000015 & $-0,32$ & 2722,2 & 30,5 & $-19,39$ & 500,0 & $-15,43$ \\
\hline & 2566 & AP-GR-M3 & 0,51165 & 0,000014 & $-0,34$ & 2557,4 & 26,1 & $-19,35$ & 500,0 & $-15,09$ \\
\hline & 2570 & AP-GR-ALA 27 & 0,51198 & 0,000013 & $-0,03$ & --- & --- & $-12,87$ & 500,0 & $-12,55$ \\
\hline
\end{tabular}


co" local).

Dados Sm-Nd deixam claro a formação híbrida do batólito, com valores de $\mathrm{T}_{\mathrm{DM}}$ paleoproterozóicos $(1,8$ a $2,0 \mathrm{Ga})$ e valores de $\varepsilon \mathrm{Nd}\left({ }_{600 \mathrm{Ma}}\right)$ bastante negativos, entre -11,0 e -14,0, o que sugere presença de protólitos derivados do embasamento (do TAP).

(c) Colônia Sta. Lucia, Mamanguape. As rochas graníticas ocorrentes em Mamanguape-Curralinho - "As Alagoas" e Colônia Santa Lúcia (centro-sul da Folha Guarabira) são caracteristicamente leucocráticas a duas micas (e granada), com preponderância de muscovita (primária, bem formada e secundária) e apresentam, textura xenomórfica a xenoblástica. Tratam-se de leucogranitos peraluminosos, composição sienogranítica predominante, muscovita onipresente. Eles se assemelham aos clássicos S-colisionais, o que é ratificado pelos dados isotópicos, sugerindo fusão crustal do embasamento do TAP.

Os dois únicos dados disponíveis de $\mathrm{T}_{\mathrm{DM}}$ indicam valores muito elevados, dos mais elevados de toda Província Borborema, ca. $3,1 \mathrm{Ga}$, e os valores de $\varepsilon \mathrm{Nd}$ (calculados para o Neoproterozóico) são fortemente negativos, entre $-15,0$ e $-17,0$. São valores surpreendentes, pois não se conhece ocorrências de rochas do Arqueano em toda a Zona Transversal da Borborema, nem resultados isotópicos de rochas graníticas similares a estas.

Esta constatação, granitos de afinidades colisionais, com fusão do embasamento do TAP, deve de imediato ser confrontado com aquele caso absolutamente distinto, dissertado abaixo para os tonalitos de Curral de Cima. Preexistem determinações $\mathrm{Rb}$-Sr para estes corpos (riquíssimos em Rubídio) feitos por brito Neves et al. (inédito), que foram reunidos uma "errocrona" apontando idade $540 \mathrm{Ma}$ (erro elevado, sem controle adequado para razão inicial), adotada como referência de tempo para o final da colisão no Brasiliano (e que são idades compatíveis com alguns dados $\mathrm{Ar}-\mathrm{Ar}$ da parte oriental do LP).

(d) O stock de Curral de Cima é corpo pequeno e alongado, equigranular, de composição tonalíticagranodiorítica (a que se somam vários outros similares dentro do LP) que se destaca por apresentar clots alinhados de hornblenda e biotita. Tratam-se de rochas tonalíticas, granodioríticas e quartzo-dioriticas (tipo arc related). Em parte, apresentam-se cisalhados pelo LP. Apresentam valores de $\mathrm{T}_{\mathrm{DM}}$ de ca. 1,5-1,3 Ga e valores $\varepsilon N d$ positivos e/ou muito fracamente negativos. Contrastam fortemente com aqueles de Mamanguape e Colônia Sta. Lúcia que estão cerca de uma dezena de quilômetros mais ao sul e sudeste Isto é diferença importante, em espaço geográfico-geológico tão restrito, e digno de nota, e de tema para investigações futuras em escala de detalhe. Para este corpo - por suas características especiais- foi feita determinação $\mathrm{U}-\mathrm{Pb}$ em zircão, sendo obtida uma idade de $623 \pm 4,1 \mathrm{Ma}$. Ao longo de toda "Depressão de Pedro Régis" há muitas outras ocorrências de stocks granodioríticos afins deste de Curral de Cima

(e) Dignos de menção são os (meta) granitói- des similares em composição àqueles de Mamanguape, mas com textura milonítica e protomilonitica, já mencionados, tipo "Rachinha" que acompanham a borda norte do TAP (vide Brito Neves et al .2001b), utilizados como pedras de revestimento. Um tema sugestivo de pesquisa futura seria investigar o contraste, ou traçar um paralelo, entre estes granitóides brasilianos de Mamanguape (de $\mathrm{T}_{\mathrm{DM}}$ bastante elevados, idade neoproterozóica), mais ao sul, e aqueles da tipologia "Rachinha" (cujos dados isotópicos indicam idades eoneoproterozóicas, do evento "Cariris Velhos"), mais ao norte. O significado e a relação entre ambos (podem representar fenômenos absolutamente distintos no tempo) são problemas em aberto e sedutores.

\section{Coberturas}

BACIAS COSTEIRA RGN-PB-PE Não existem afloramentos conspícuos das unidades estratigráficas desta bacia costeira na folha de Guarabira, estando seus sedimentos do Cretáceo quase sempre acobertados pelo Grupo Barreiras, pelas "Areias Brancas" e/ou por elúvios de dificil identificação. Há alguns afloramentos esparsos e restritos da Formação Beberibe, e esta unidade pode estar ocorrendo amplamente sob coberturas diversas. Essta constatação é absolutamente nova, posto que jamais esta unidade foi cartografada na folha Guarabira e adjacentes a leste e oeste, e isto seria plenamente possível em escalas maiores. Complicador deste quadro é o contingente notável de falhamentos modernos, pós-Cretáceo e pós-pliocênicos (cortam o Barreiras), cuja repercussão imediata é o escalonamento de patamares/platôs sedimentares, já dissertados nos itens iniciais e nas figuras 1 a 4 . As linhas de falhas (WSW-ESE) que alinham os rios Miriri, Mamanguape, Gupiúna, Camaratuba (LP), Duas Estradas etc. são de grande importância neste sentido.

As raras exposições do embasamento pré-Cambriano entre Recife e Natal (ao longo da BR-101) estão nas folhas de João Pessoa e Guarabira, e nesta justamente no bloco alto da falha de Mamanguape (também na zona de falha/talweg do Rio Miriri, e no talweg do Camaratuba, na estrada para Jacaraú, PB-071). Ali se expõem rochas de natureza metagrauváquicas (do TAP), nas vertentes dos rios mencionados, e um conjunto de rochas graníticas (tipo Mamanguape na BR101 e tipo Curral de Cima na PB-071).

Para os sedimentos desta bacia há trabalhos recentes de revisão, de caráter mais amplo, com respaldo em sondagens elétricas e poços tubulares, entre João Pessoa-PB e Touros-RN, conduzido por Feitosa et al. (2002) e Barbosa et al. (2002), os quais dissertam o quadro litoestratigráfico presente e a sua compartimentação estrutural, a qual obedece àqueles falhamentos diagonais à costa já mencionados. Estes trabalhos, recomendados para leitura, liberam os presentes autores de detalhamentos sobre a Bacia. Há vários outros trabalhos de síntese para esta bacia, entre já publicados, e inéditos (dissertações de mestrados e teses de doutora- 
mento) a serem consultados. Mas, no desenvolvimento desta pesquisa, vários problemas estratigráficos foram detectados, ainda em aberto, principalmente no tocante os domínios de ocorrência da Formação Beberibe

O "Alto de Mamanguape", cuja expressão em campo foi mencionada, em sub-superfície é apontado como o limite provável entre a extensão para o sul da Bacia Potiguar (os carbonatos da Formação Jandaira são por ele bruscamente truncados) e a Bacia Pernambuco-Paraíba (que tem sua unidade Beberibe Inferior barrado pelo alto, que se deixa ultrapassar pela Unidade Beberibe Superior, que segue para norte até o Alto de Touros). Esta unidade, Beberibe Superior, como já comentado, tem esparsas áreas de afloramento na Folha Guarabira (cuja extensão/expressão em cartografia geológica carece ser feita). Uma série de altos do embasamento foi identificada no trabalho de Feitosa et al. (2002), como Mamanguape, Goianinha, Nísia Floresta, Macaíba-Parnamirim, até o alto de Touros (que delimita os depósitos advindos de Pernambuco e Paraíba).

UNIDADE / COMPLEXO (PARA) ESTRATIGRÁFICA PIRIRI DO VIGÁRIO -UEPV A Unidade Estratigráfica Piriri do Vigário - UEPV - (designação informal aqui introduzida), cobre a parte centro oriental da Folha de Guarabira. Subjacente ao Grupo Barreiras está sobreposta aos ortognaisses cisalhados do TAP, principalmente no trecho a leste do horse tail originado na zona de falha Galante-Serra Redonda. Esta unidade está moldada na forma de tabuleiro, cerca de até $100 \mathrm{~m}$ acima do nível de cotas do cristalino peneplanizado (as "chãs"), se ajustando às frações de tabuleiros dos sedimentos costeiros (patamar de Maripitanga-BR 101, ca. $200 \mathrm{~m}$ ), sobre o qual algumas estruturas circulares quilométricas são facilmente detectadas - (detectadas melhor em aerofotos 1/70 000).

Destaques adicionais são a sua composição litológica complexa (diversificada), origem problemática, idade discutível (posição pré-Barreiras?), e mais ainda, processo evolutivo. Sob a parte mais interior desta cobertura estão anomalias magnetométricas e gravimétricas importantes, sendo que a extensão lateral da unidade excede em muito o domínio das zonas anômalas. A UEPV extrapolou a área das suas prováveis rochas fontes sotopostas.

A complexidade desta unidade se revela francamente ao nível meso e macroscópico (análise de campo) e mais ainda quando se recorre à microscopia e às análises geoquímicas, quando se recorre às escalas de detalhe. Para o momento serão focados aspectos descritivos gerais e ter de aguardar com humildade e cautela os estudos posteriores (furos estratigráficos são imprescindíveis para tal). É preciso avançar passo a passo, com outros recursos da geologia de superfície (minerais pesados, sedimentos de corrente) e de subsuperfície (furos, já em realização pela mineradora que requereu a área), inclusive da intensificação da pesquisa geofísica.
Descrição macroscópica e microscópica preliminar da UEPV De um total de 38 amostras coletadas na região de Itapororoca e arredores para uma descrição preliminar meso e microscópica três grandes grupos foram distinguidos a saber: i) Grupo I, constituído por amostras de materiais altamente alterados; ii) Grupo II de amostras alteradas e iii) Grupo III constituído de amostras não alteradas. Cada qual desses grupos analisados microscopicamente apresentaram semelhanças estruturais, com particularidades no contexto textural e composicional.

No Grupo I distingue-se matriz de composição silicática extremamente fina (sílica criptocristalina). Em lâmina observa-se quantidade significativa de material marrom, variando em de tonalidade para porções mais escuras em uma faciologia a feições mais claras em outra. Essas coexistem com diversos minerais primários constituintes, os quais exibem oxidação e o principal mineral identificado é a goethita. Tal matriz possui composição poliminerálica (muitos opacos como magnetita exsolvida com ilmenita). Estas estruturas são freqüentemente perpassadas por microveios de sílica indicativos de fluxo em textura microcristalina fina. Em observação microscópica este fluxo exerce orientação em alguns macro-grãos de quartzo (bem cristalizados) onde alguns destes exibem feições de corrosão.

Em algumas das laminas petrográficas destas rochas foi observada com certa constância, textura do tipo mitocondrial (delimitação provisória na ausência de termo mais adequado). O cenário predominante neste caso consiste de grãos de quartzo na amostra, isolados e com morfologia ovalada, alongada e eventualmente em feição semelhante a "micritico". Em visão microscópica estes fragmentos encontram-se subdivididos formando espécie de "puzzle", com seus contatos preenchidos por um material amarelo esverdeado não identificado tanto em luz natural como polarizada.

Pertencem ainda ao Grupo I feições macroscópicas interessantes. Por exemplo, na fonte e piscina da cidade Itapororoca, foram encontrados diversos blocos de material intemperizado exibindo sob todos os aspectos possíveis indicação de se tratar de "bombas vulcânicas" (matriz fina, indicação de ejeção, fraturamentos radiais, indícios de resfriamento rápido etc.). Nesse mesmo grupo, na porção superior formada pela unidade encontra-se frente de seixos de quartzo imersos em matriz microcristalina quartzosa fina indicando sob todos os aspectos fluxo similar a derrames de lava de caráter plástico em superfície, visto que os seixos de quartzo leitoso são arredondados e maciços, indicando proveniência de atividade fluvial, provavelmente amealhados quando da instalação desse derrame vulcânico.

O Grupo II apresenta matriz microfibrosa em luz natural, de aspecto microcristalino fino contendo minerais em início de oxidação (cores marrons escuras e claras) em contato direto com microveios de quartzo dispersos cortando irregularmente a matriz desse material, o que lhe confere aspecto de movimento vulcânico com certa plasticidade. Diversos minerais opacos ocorrem nesta matriz sendo os principais e prontamente 
identificados, magnetitas que exibem exsolução com ilmenita. Parte destes opacos exibe corrosão mecânica e não química, demarcados pela matriz que denota ser constituída predominantemente por hidróxidos de ferro onde goethita é o mineral de destaque neste caso. Nesta estrutura são destacadas cavidades cujas bordas encontram-se preenchidas por quartzo microcristalino. Neste caso, tais amostras exibem textura fortemente microcristalina, destacando-o das características menos expressivas nesse aspecto apresentados pelos outros materiais aqui analisados (amostras do Grupo I e III).

Nas amostras definidas como alteradas (Grupo II), evidencia-se com bastante nitidez preservação de estruturas primárias de deformação, provavelmente metamórfica, as quais sugerem serem produzidas movimento da matriz em estado plástico (movimento de rotação de minerais no interior da matriz sugerindo fluxo desses) como pode ser observado nas diversas laminas analisadas. Este aspecto é dado por fragmentos de magnetita exsolvida com ilmenita, rotacionados e parcialmente "pulverizados", adquirindo em seção delgada habito circular o que se pressupõe sejam esféricos tridimensionalmente. O Grupo III exibe em quase totalidade das amostras de lâminas analisadas, matriz com ausência de material matricial e fundo de coloração avermelhada, seja escura ou clara (indicando inexistência de processo de oxidação dos minerais ou matriz ai existentes) o que os distingue bastante dos outros dois grupos.

A maioria das lâminas é composta de minerais opacos ocupando parte importante da massa matricial, levando a sugestão de que essa matriz encontrava-se em estado plástico quando da formação dessa textura. Tal evidencia tem sustentação quando analisados os microveios de quartzo os quais exibem diversas interseções de microveios sendo cortados uns pelos outros em clara relação cronológica de posterioridade, o que confere clara relação de varias etapas de injeção de sílica na construção desse tipo litológico. Por outro lado microveios compostos também de sílica microcristalina cortam a matriz microcristalina de sílica, sugerindo remobilização e reinserção de sílica em condições fluidas, em uma matriz mantendo certa plasticidade.

Algumas considerações genéticas sobre o material (do $U E P V)$ analisado $\mathrm{O}$ cenário apresentado pelas diversas texturas e estruturas observadas tanto na escala microscópica como macroscópica, embora sejam meramente descritivas e em alguns casos sugeridos termos para algumas destas feições; permite-se, respeitando este aspecto, adiantar considerações de ordem genética no que se refere ao (s) processo (s) de formação da UEPV.

Se por um lado há forte tendência de se inferir indicio de fragmentação (evento termo-sísmicomagmático) para as amostras portadoras de textura de aspecto "mitocondrial" (Grupo I), visto ser esta feição ser típica de mecanismo magmático, por outro lado, processos metamórficos, em raros casos, podem também promover tais texturas e estruturas concernentes as relações de fraturas preenchidas e feições sobre alguns minerais (caso do quartzo micritico). Embora estas estruturas e texturas sejam preferenciais de um ou outro grupo aqui descrito, a divisão em grupos foi construída em um cenário de campo visto que todos as amostras coletadas pertencem, em princípio, a uma mesma variedade de material litológico, sendo esse, mais ou menos modificado por diversos processos (ora com vocação tectono-magmatico-metamórfico, ora com vocação intempérico-geoquímico).

Diversas evidências de remobilização de sílica gerando microveios permitem sugerir eventos cronológicos distintos de injeção de sílica no sistema constituído por este material litológico e esses, indicam também os diversos sentidos (direção) desses fluxos notados nas diversas lâminas analisadas. Em tal contexto, esses eventos poderiam ter ocorrido de modo simultâneo ou mesmo não síncronos. A homogeneidade apresentada pela composição mineral, o aspecto textural e estrutural desse material indicam a possibilidade dos mesmos terem se formado às expensas de processos magmáticos ou metamórficos ou ambos, o que tende a excluir a possibilidade de provirem de um mecanismo do tipo intempérico geoquímico. Do ponto de vista magmático, o processo mais provável conduz a uma origem hidrotermal, com abundante solubilização de sílica, com elevado aporte de flúor e metais. A abundância encontrada de flúor em análises de fluorescência de raios X induz a essa interpretação visto ser este elemento freqüente em processos hidrotermais.

Considerações lito-estratigráficas Na verdade, os litossomas tabulares da UEPV (basculados de 1 a 3 graus para norte e nordeste) reúnem uma série de características, a serem dissertadas, que distinguem e colocam esta unidade além das definições usuais de duricrust e silcrete (registro de ocorrências também de transformações de ígneas e outros processos exogenéticos). Foram verificados presenças de pelo menos dois níveis de desenvolvimentos de solos (na base e no topo da unidade), e a possibilidade de níveis outros de desenvolvimento de solos (linhas de seixos, pelo menos) na porção média da unidade.

Na parte basal da unidade (localidade de Mendonça e da Destilaria Xuá) verificamos a formação da unidade com preservação nítida de restos do embasamento nela inseridos: frações dos ortognaisses (restos da foliação preservados) e de diques de quartzo, envolvidos no processo de silicificação, qual é recorrente de uma parte a outra da unidade, sintomaticamente em mais de uma etapa.

Os processos de hidrotermalismo são muito importante em diversas frações da unidade, sendo o componente de sílica (teores entre $75 \%$ e $93 \%$ ) mais elevados nas rochas mais sãs, formando algumas rochas onde praticamente toda a massa é silicosa, e onde há recorrência (veios, drusas de quartzo, preenchimento de fraturas abertas em rochas previamente já silicificadas etc.) franca de processos complementares. Há casos/ amostras absolutamente transformadas em silexitos.

$\mathrm{O}$ registro de atividades sedimentares durante 
a evolução da unidade está presente em diversos tipos de brechas (primárias, secundárias intraformacionais) com fragmentos de quartzo, de quartzitos, de palhetas de mica branca, vieiros silicosos, e mais raramente fragmentos de rochas ígneas. Algumas destas brechas lembram àquelas de formação piroclástica, mas não podemos afirmar isto com segurança pela precariedade das observações possíveis em lâmina.

$\mathrm{Na}$ Fazenda Mendonça ("empréstimo" rodoviário) e na Faz. Timbó (poço de cerca de $10 \mathrm{~m}$ ) é possível observar estratos relativamente bem desenvolvidos, o caráter "estratificado" paralelo às linhas do tempo, embora o aspecto maciço e a silicificação preponderante sejam fatores limitantes das observações de feições sedimentares.

A problemática de origem e evolução do UEPV não pode ser encerrada no presente texto, sendo necessário amplo leque de estudos específicos, em escalas de detalhe (em superfície e sub-superfície). Para o momento, temos que nos contentar com sua expressão na geologia regional e as descrições acima consignadas.

Utilizando as premissas do código de nomenclatura internacional para unidades litoestratigráficas (Salvador 1994) e as observações acima, a classificação ideal seria a de "Complexo". Nem de "formação" e nem de "grupo", posto que estão consignadas diferentes classes de rochas (diferentemente afetadas), mistura litológica irregular, complicada relações estruturais/temporais entre elas (seqüência original de componentes obscurecidas), e ainda a impossibilidade de se chegar a individualização de rochas ou seqüência de rochas por mapeamento convencional (pelo menos, isto é muito difícil). A posição pré-Barreiras é aparente, obtida do levantamento expedito regional (há restos de conglomerados tipo Barreiras sobre a UEPV), pois a inconsistência dos depósitos do Barreiras não permitiu um contato flagrante, e a extensão regional do UEPV para o sul da folha, como remanescentes mal preservados (Cuité do Mamanguape, Minador de Baixo, Estacada etc.) deixa esta possibilidade em aberto. A escolha da designação UEPV, informal, e para-estratigráfica é a mais cautelosas e a menos inconsistente no momento.

Analisando as diversas propostas estratigráficas para o Grupo Barreiras verificam-se divergências irreconciliáveis, mesmo nas áreas com controle de subsuperfície. A proposta mais moderna (diversos autores da Petrobrás, reunidos por Moraes \& Alkmim 1998) ali apresentada coloca o Barreiras no Neomioceno-Plioceno, sobrejacente à Formação Tibau (onde há vulcanismo basáltico alcalino importante, idade paleógenaeoneógena). No momento, o pensamento dos autores é no sentido de algum tipo de vinculação entre o magmatismo Macau (Eoceno-Oligoceno), ocorrente na parte oriental da Borborema, e os processos precursores/criadores do UEPV. Mas, isto carece investigação complementar.

É necessário se aguardar os resultados das sondagens (em processo na área) para melhor conhecimento da unidade. Por enquanto, as melhores secções-tipo são aquelas ao longo das estradas Itapororoca, Cam- pinas, do Riacho Timbó (parte mais elevada do platô de Piriri do Vigário) para a Fazenda Formigueiro e do ramal que daí vai para o sul para Quatigereba (Concris, centro da estrutura circular maior). Nas localidades de Mendonça (empréstimo rodoviário) e nas imediações da Destilaria Xuá há perfis excelentes da parte basal da unidade, com silicificação de rochas do embasamento (migmatitos).

Nos cimos do platô de UEPV, encontramos localmente restos de ferricrete conglomerático, o que pode apontar UEPV como substrato para unidade UPEN (a ser discutida), mas estas são observações preliminares, não conclusivas.

UNIDADE PEDOESTRATIGRÁFICA ENGENHO NOVO (UPEN) A unidade pedoestratigráfica Engenho Novo (Brito Neves et al. 2005), recentemente proposta, aparece na Folha Guarabira, sob os sedimentos mesozóicos e cenozóicos (formando uma sapata sobre o embasamento) nos talwegs dos vales principais (Mamanguape, Camaratuba) e na parte mais ocidental do tabuleiro de Capim-Cuité do Mamanguape, na forma de ferricretes conglomeráticos (e/ou de cascalheiras desmanteladas), sendo algumas vezes difícil sua separação cartográfica do Barreiras. Esta unidade pedogenética de idade ainda desconhecida (pré-Barreiras? Pré-Beberibe?) que acoberta clara e extensivamente o embasamento pré-Cambriano s. 1., ocorre ocasionalmente como remanescentes ferruginosos conglomeráticos, bem no topo da fração de tabuleiro (ca. 200m) soerguida e sustentada pelo UEPV (pós UEPV), na região entre Timbó e Quatigereba. O estudo desta unidade pedogenética e de sua idade está em processo e são as poucas ocorrências cartografadas até o presente na folha Guarabira, mas é necessário enfatizar sua notável extensão e preservação na Folha Sapé, ao sul.

Da fronteira de Paraíba com Pernambuco ao sul (cidades de També, Juripiranga e Ferreiros) até a fronteira da Paraíba com o Rio Grande do Norte, esta unidade pedogenética ocorre, em todo o leste da Paraíba, em grande parte sobre rochas do embasamento (TAM e TAP), e em parte ocorre lastreando os sedimentos da Bacia Costeira. Nenhum trabalho anterior nesta região há menções sobre UPEN, de grande importância, não só pela extensão geográfica, mas principalmente pelo significado no contexto da evolução geomórfica da Província como um todo. $\mathrm{O}$ trabalho de preliminar de Brito Neves et al. (2005) é exclusivo, mas não conclusivo e carece de continuidade.

GRUPO BARREIRAS A farta bibliografia e as freqüentes revisões do Grupo Barreiras (vide Alheiros e Lima Filho 1991), entre outros, com descrição de fácies areníticos-conglomeráticos aparentemente nos exime da necessidade de novas considerações, pois não foram encontradas novidades no cartel lito-estratigráfico geral (salvo quanto às possibilidades de ocorrências, já comentadas, da Formação Beberibe no contexto indiferenciado dos tabuleiros). No Barreiras predominam depósitos areno-argilosos, de sistemas fluviais entrela- 
çados, interagindo com leques aluviais distais. Trata-se de sistemas fluviais de baixa a alta sinuosidade, com influências locais de fácies litorâneas e de planície de maré (estas não foram detectadas na folha de Guarabira). São, em geral, depósitos de areias quartzosas e subarcoseanas, com feldspatos argilizados, muitas vezes variegados (cores diversas dependendo do nível de oxidação), intercalados com níveis argilosos (caulinita predominante) e de siltitos de dimensões decimétricas. $\mathrm{Na}$ base dos tabuleiros, nas vertentes dos vários rios regionais aparecem níveis conglomeráticos com matriz areno-argilosa, monomíctico que pode atingir até $10 \mathrm{~m}$ de espessura.

A separação cartográfica concreta e correta do Grupo Barreiras das unidades sotopostas (UEPV, UPEN, Formação Beberibe) só será possível em escalas de mapeamento de 1/50 000 e superiores.

O que deve ser destacado são as variações de espessuras nos diferentes patamares, de diferentes cotas, que foram observados de sul para o norte, da Folha de Sapé (sul) para a folha de S. José do Mipibu (norte), todos eles (patamares e espessuras) condicionados pelo jogo de falhas. Isto é algo que jamais foi dissertado, e pode ter implicações diretas na distribuição/colocação do Barreiras e do Beberibe.

Como já descritos, há patamares de cotas de $100 \mathrm{~m}$ com espessuras modestas do Barreiras, até 3040m, como aqueles da BR-230, na folha Sapé ao sul, e aquele na mesopotâmia Mamanguape-Miriri (entre Capim e a BR-101). Há patamares na cota de $200 \mathrm{~m}$, com espessuras do Barreiras (+ Beberibe?) de até $100 \mathrm{~m}$, como aqueles dos altos cursos dos riachos Palmeira e Curralinho (nordeste da folha de Sapé, ao sul do Patamar Capim-Br-101, e aquele de Maripitanga-alto curso do riacho Barro Branco, ao norte de Mamanguape etc., conforme já abordado no item da geomorfologia. Esta disposição de distintos patamares, com interveniência de falhamentos (rios orientados) pode está mascarando ocorrências/exposições da Formação Beberibe (sobAreias Brancas), e só a cartografia de detalhe pode definir estes fatos.

Toda parte mais oriental do terreno SJC (parte oriental do RGN) está coberta por sedimentos (Grupo Barreiras ?), como já descrito, no patamar de Jacaraú, que pode ser ainda subdividido (zonas dentro da "depressão de Pedro Régis" e ao norte dela). Ou seja, é possível reconhecer o patamar mais ao norte (Jacaraúfronteira PB-RN, com cotas superiores a $250 \mathrm{~m}$ em alguns pontos, e ca. $200 \mathrm{~m}$ em outros) e outro mais ao sul, Rio Pitanga (geralmente $<200 \mathrm{~m}$ ). As Areias Brancas cobrem especialmente as áreas mais elevadas da porção norte, mas também se encontram presentes mais para oeste, por sobre o embasamento, tudo isto reclamando mapeamento em escalas maiores.

"AREIAS BRANCAS", CASCALHEIRAS, ALUVI$\tilde{O} E S$ (a) As "Areias Brancas" se dispõem sobre o Grupo Barreiras e unidades subjacentes em várias áreas. Observáveis facilmente ao longo da BR-101 (norte de Mamanguape) e da rodovia PB-071 (para Jacaraú).
Para separá-las cartograficamente dos sedimentos subjacentes é um pouco difícil, carece detalhamento, como já mencionado. Trata-se de uma unidade lito-estratigráfica informal, de provável origem elúvio-coluvionar, carente de mapeamento e de estudos específicos. As explicações vigentes usuais em muitas referências anteriores como "podzol" ou como produtos de intemperismo do Barreiras (e/ou de arenização da Formação Beberibe da Bacia Costeira), terraços marinhos etc. Mas, todas estas são observações tão genéricas como incompletas e cuja fundamentação requer muitas etapas de pesquisa para o futuro, caso a caso. Circunstancialmente, a oeste de També, folha de Sapé, ao sul, estas "areias brancas" recobrem embasamento de rochas graníticas (onde claramente é eluvional).

Em geral, nos tabuleiros mais elevados há ocorrências de "Areias Brancas", geralmente areias brancas (por vezes amareladas e até avermelhadas) de possanças inferiores a 10m. Na Folha Guarabira elas ocorrem abundantemente nos patamares de Maripitanga e Jacaraú (neste caso, ocupando os topos). Ao largo da reserva indígena Potiguara, norte de Mamanguape, as ocorrências são muito expressivas. São areias geralmente claras, uniformes, bem selecionadas, com menos de $20 \%$ de silte e argila. Só muito localmente apresentam estratificação, marcada por vários níveis de solos orgânicos e discordâncias sub-paralelas, com presença inclusive de estilólitos. Muito provavelmente estas areias são provenientes de distintas fontes e processos. Reitera-se aqui a necessidade imperiosa de se estudar caso a caso.

(b) Comumente, as manchas residuais de UEPV (e /ou de UEPN) ocorrem sobre as rochas do embasamento (sobre as "chãs"), com a presença de tapetes de clastos (cascalheiras oligomícticas, blocos de quartzo, de arenítos, de silexitos etc.), evidenciando a ação de processos coluvionares tardios, com remobilização (remoção e re-sedimentação moderna) de seus primeiros elementos litogenéticos. Nestas áreas atapetadas de clastos (silexitos, quartzo etc. ) costuma fluir água subterrânea (vadosas de aquífugo, águas suspensas), ou seja, as zonas de contatos sempre muito úmidas. Várias ocorrências de cascalheiras foram observadas ao sul das áreas do UEPV (e do UEPN) discriminadas no mapa da Fig. 1. Algumas ocorrem mais ao norte e ao sul da área principal do UEPV, em cotas entre 80 e $100 \mathrm{~m}$. A correlação destes níveis de cascalheiras pode ser feita com a UEPV (restos) ou com restos da UPEN, e não há termo conclusivo sem mapeamento de detalhe para o futuro.

Os aluviões são expressivos nos principais rios regionais, especialmente no Camaratuba (que é um grande colimador de águas subterrâneas) advindas dos altos dos platôs sedimentares. Mas também ocorrem no Mamanguape, onde a planície aluvial atinge cerca de 6 $\mathrm{km}$ de largura, no leste de Mamanguape, sendo predominantes associações areno-argilosas.

Por fim, é preciso reiterar que os quadros litoestratigráfico e crono-estratigráfico dos sedimentos fa- 
nerozóicos em geral, nas Folhas de Guarabira e Sapé (e na faixa costeira como um todo) imprescindem de refinamento. Os trabalhos de Barbosa et al. 2002 e Feitosa et al. 2002 e várias sínteses anteriores originadas na UFPE e UFRN têm sua validade, mas há muitos problemas em aberto, inclusive de cartografia geológica básica.

As unidades UEPV e UEPN não têm idades conhecidas de fato, a atribuição de Barreiras ao Neomioceno-Plioceno carece de melhor fundamentação (paleontológica, por exemplo). A Unidade "Areias Brancas" é tema absolutamente aberto e amplo para estudos de procedência, gênese e idade (estratigrafia, de modo geral), com várias possibilidades de abordagem. $\mathrm{O}$ entendimento das crostas ferruginosas tipo UPEN, que de certa forma pode servir como marcadores geomorfológicos e estratigráficos, é absolutamente incompleto.

MAGNETOMETRIA O estudo magnetométrico utilizou o aerolevantamento 2019 da Companhia de Pes- quisas de Recursos Minerais (CPRM)/NUCLEBRÁS/ LASA (1976), denominado "Projeto Esperança", e que cobriu a área de $36^{\circ} 25^{\prime} \mathrm{W}-35^{\circ} 25^{\prime} \mathrm{E} ; 6^{\circ} 00^{\prime} \mathrm{N}-8^{\circ}$ $00^{\prime} \mathrm{S}$, que se encontra a leste dos estados da Paraíba e do Rio Grande do Norte. As medidas foram efetuadas pela LASA, no período novembro de 1975 a março de 1976. Infelizmente, o levantamento 2019 não cobriu totalmente a área de interesse, ficando descoberta a metade oriental da mesma. Observa-se no detalhe da figura 5 que no extremo leste a anomalia em correspondência à unidade Piriri do Vigário está truncada.

O comprimento total dos perfis percorridos foi de $19.170 \mathrm{~km}$, com um intervalo de amostragem de $1 \mathrm{~s}$. Os perfis, espaçados entre si de $1 \mathrm{~km}$ foram percorridos na direção N-S sendo de $150 \mathrm{~m}$ a altura nominal de vôo. As linhas fiduciais foram percorridas na direção E-W com espaçamento relativo de $20 \mathrm{~km}$. O levantamento cobriu uma área de $19.000 \mathrm{~km}^{2}$.

Os dados disponibilizados pela CPRM são representados na figura 5A. Observa-se a anomalia mag-

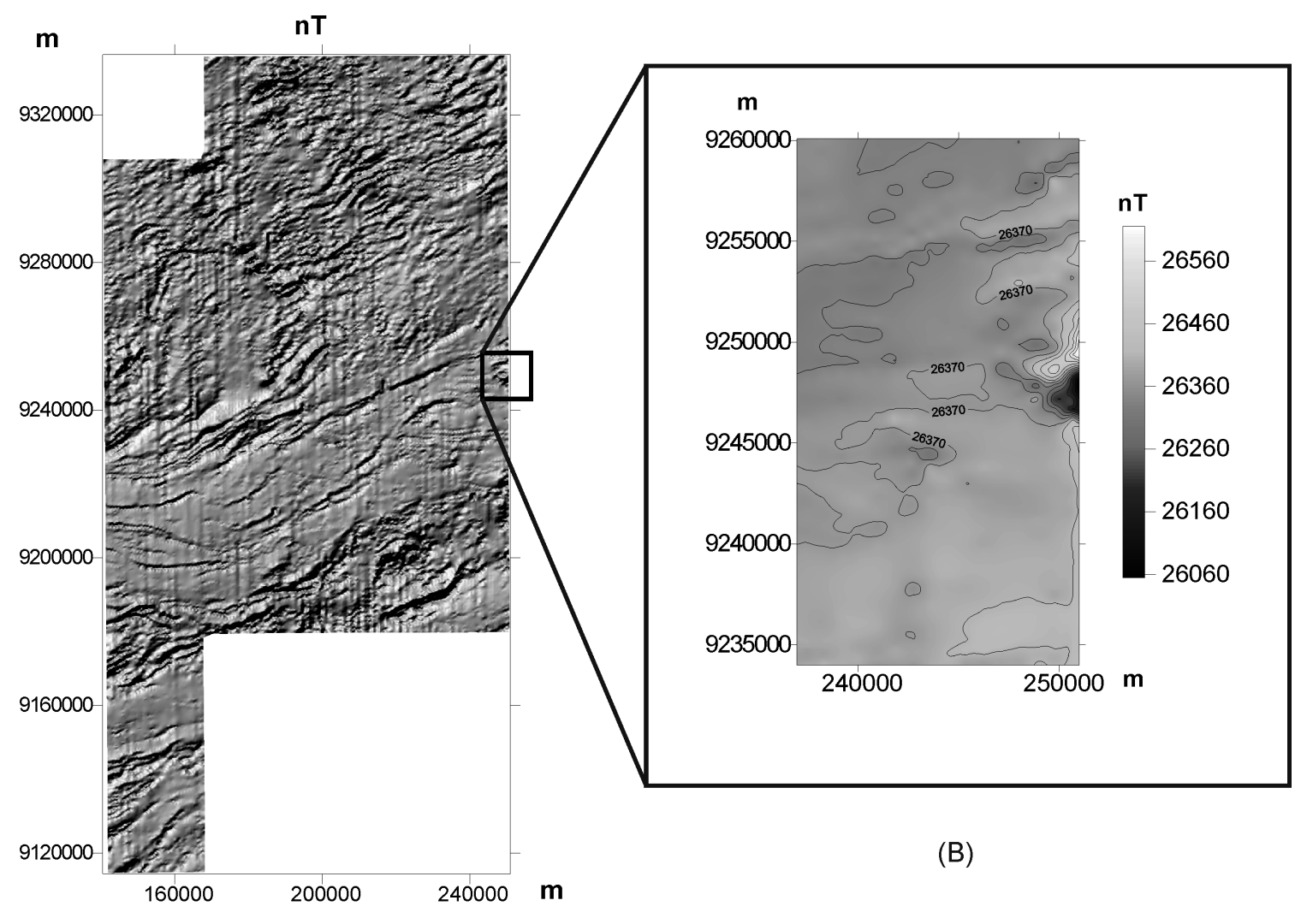

(A)

Figura 5 - Localização e detalhamento da anomalia magnética na área de estudo em relação ao aero-levantamento 2019 da CPRM. (A) Anomalia magnética do Projeto Aerogeofísico Esperança, sob forma de relevo com iluminação de $135^{\circ}$ de azimute e $80^{\circ}$ de inclinação. Ao sinal medido com aeromagnetômetro de prótons, modelo G-803 da Geometrics, foram aplicadas as correções de variação da altitude de vôo e das variações diurnas medidas na base. As coordenadas são fornecidas na Projeção Equatorial de Mercator. Os valores sobre toda a área variam no intervalo de 25.500 $n T$ a $26.750 n T$. A área quadrada, demarcada no centro da borda oriental é sítio do detalhamento gravimétrico, onde se encontra a denominada anomalia de Itapororoca, com características $3 D$. (B) Detalhe da componente magnética da anomalia de Itapororoca, que apresenta polaridade normal. 
nética residual na região coberta pelo Projeto Esperança, sob forma de relevo sombreado, com uma iluminação direcional tendo $135^{\circ}$ de azimute e $80^{\circ}$ de inclinação, valores geralmente utilizados para realçar os gradientes. A interpolação foi feita sobre uma malha regular, utilizando o algoritmo da mínima curvatura, através do aplicativo SURFER da "Golden Software". Verificamse feições geológicas de interesse com marcante distinção dos terrenos Rio Grande do Norte (ao norte) e Alto Pajeú (ao centro) separados pelo Lineamento de Patos (LP), e o terreno Alto Moxotó (ao sul). As interpretações geológicas e geocronológicas prévias ao levantamento são corroboradas pela resposta aeromagnética.

A região de detalhamento gravimétrico é assinalada pelo retângulo na mesma figura, ampliado ao lado. Destaca-se nesse retângulo (Fig. 5B) uma anomalia bipolar, localizada no extremo leste do levantamento, e a norte de Itapororoca, que é a resposta magnética característica de corpos com geometria 3D. Infelizmente, por estar no limite do levantamento, é possível apreciar o registro magnético dessa importante anomalia apenas de forma qualitativa. Na figura 6 foi antecipada uma sobreposição do campo anômalo magnético residual (sombreado) com amplitude de 140nT com o campo anômalo gravimétrico a ser descrito nas páginas seguintes. A Unidade Piriri do Vigário se situa ao redor e sobre a junção dos dois levantamentos.

\section{GRAVIMETRIA}

Levantamentos Efetuados O levantamento gravimétrico, executado especificamente para o estudo do corpo em correspondência da anomalia anteriormente mencionada, percorreu, estradas, vias secundárias, trilhas e caminhos, resultando num levantamento de semi-detalhe. A região levantada abrange uma área muito maior daquela representada na figura 6 , uma vez que a análise dos dados requer um bom conhecimento do campo regional. As medidas foram realizadas com um gravímetro LaCoste \& Romberg, modelo G com níveis eletrônicos e painel de leitura eletrônica, e munido de um dispositivo analógico de re-alimentação, que permite obter precisão da ordem de $0,04 \mu \mathrm{Gal}$.

Para a medida da altitude de cada estação (vide Fig. 7) utilizou-se o método barométrico com base fixa. Todas as medidas foram referidas à Rede de Nivelamento do IBGE, e a metodologia utilizada é descrita adiante em detalhe.

Todas as medidas gravimétricas do levantamento aqui descrito foram referidas à RGFB tomando como referência a EG de João Pessoa "B" (PB) implantada pelo Observatório Nacional em correspondência à Referência de Nível (RN) 396-A do IBGE (47,36 m s.n.m.), localizada na soleira da Catedral Metropolitana Nossa Senhora das Neves, na Praça Dom Ulrico (RF0060), tendo como valor $\mathrm{G}=978135.483 \mathrm{mGal}$. Para fins de controle, foi reocupada a EG de Goiana "B" (RF0061) na cidade de Goiana, tendo como valor $\mathrm{G}=978151,310 \mathrm{mGal}$.

Para fins de viabilização na logística, efetuou-se transporte da estação de referência RF0060 para Guara-

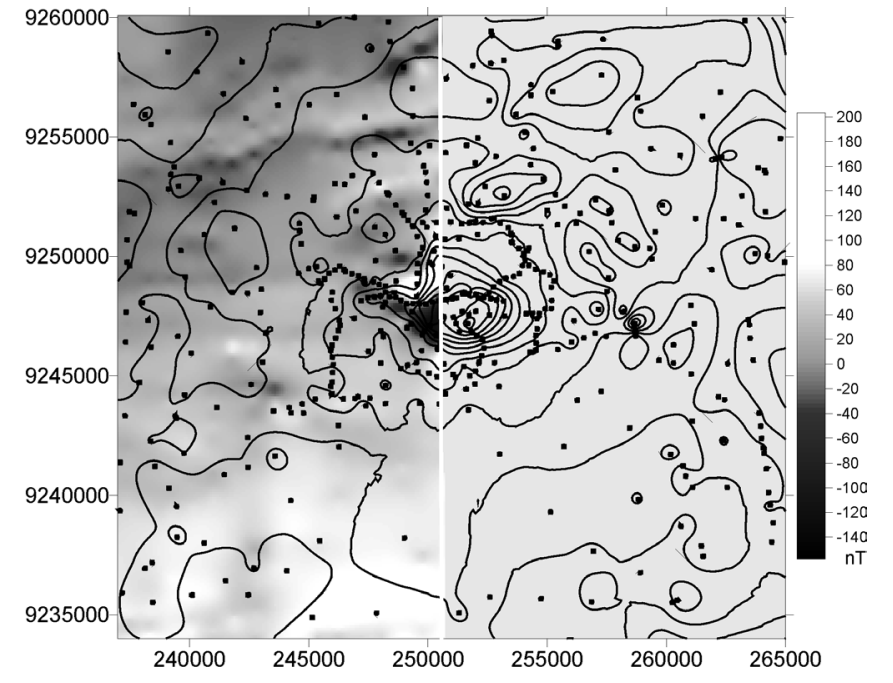

Figura 6 - Superposição do campo anômalo magnético residual (sombreado) com amplitude de $140 \mathrm{nT}$, após subtraída a componente do Campo Geomagnético de Referência Internacional (IGRF) com o campo anômalo gravimétrico linhas de contorno) na área de destaque. As coordenadas estão na Projeção Cônica de Mercator referida ao Datum de "Córrego Alegre". Observa-se a continuidade da anomalia gravimétrica na porção onde aquela magnética foi truncada em vista do limite do levantamento aéreo. Os pontos correspondem à localização das estações gravimétricas.

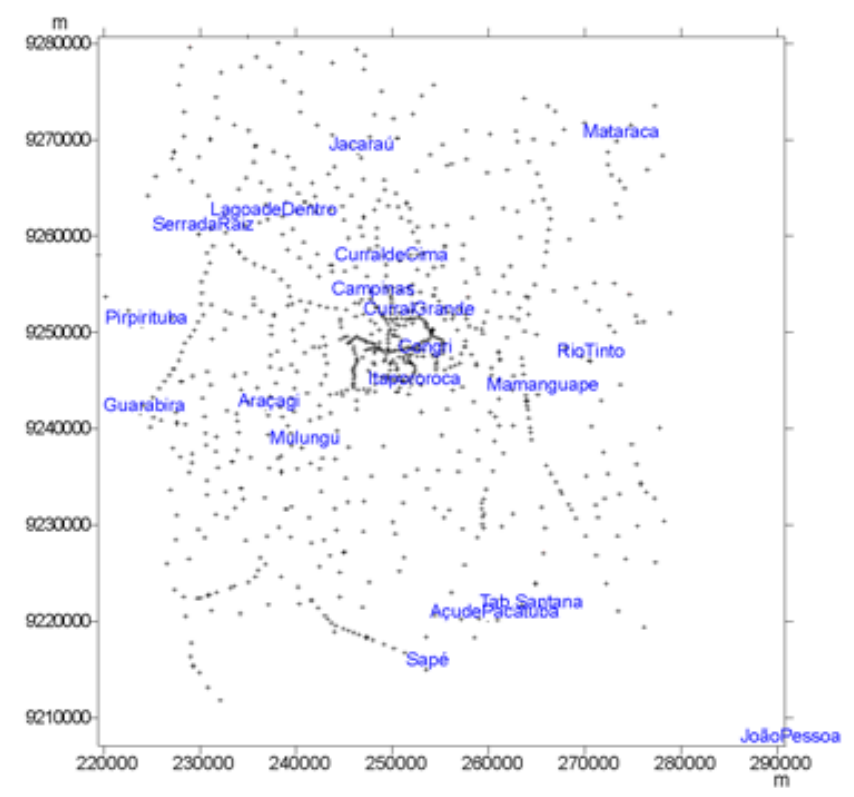

Figura 7 - Esboço das estações gravimétricas implantadas com as principais localidades (cidades/vilas regionais) para referência.

bira, Itapororoca, Mamanguape e Araçagi (Tab. 2).

As referências de nível (RN) utilizadas na região, implantadas pelo IBGE (Tab. 3) serviram de base 
Tabela 2 - Valores de gravidade de referência

\begin{tabular}{l|c|c}
\hline Tabela I & $\begin{array}{c}\text { Valores de referência } \\
(\mathrm{mGal})\end{array}$ & Estação \\
\hline RF0060 & 978135.510 & João Pessoa “B” (PB) \\
\hline RF0062P & 978076.889 & Guarabira (PB) \\
\hline RF0063P & 978098.683 & Itapororoca(PB) \\
\hline RF0064P & 978121.401 & Mamanguape(PB) \\
\hline RF0065P & 978090.057 & Araçagi(PB) \\
\hline
\end{tabular}

para o levantamento altimétrico por barometria. A altitude foi medida em correspondência a cada estação gravimétrica levantada.

As bases altimétricas, para áreas num raio inferior a $30 \mathrm{~km}$ e desníveis altimétricos inferiores a $200 \mathrm{~m}$, foram transportadas da $\mathrm{RN}$ mais próxima (Tab. 2) para o local onde eram efetuadas medidas de altimetria por pressão atmosférica, umidade e temperatura a cada 10 minutos.

Para a base fixa foram utilizados dois altímetros barométricos digitais "Air-DB Intellisensor" e um altímetro analógico Thommen enquanto que, na estação móvel, foram utilizados dois altímetros Thommen e um altímetro digital portátil da Intellisensor, modelo manual. Seja na base fixa como na estação itinerante, as medidas de temperatura e umidade utilizaram psicrômetros de aspiração da marca Yope, efetuando-se leituras de temperatura com o bulbo seco e úmido. A distribuição dos erros para esse método de medida, tem como desvio padrão aproximadamente 0,5 metros, representando menos de 0,2 mGal na medida de g (McLintock et al. 1994). Note-se que a incerteza na medida da altimetria, de muito supera as demais envolvidas no cálculo da propagação de erros.

O desvio padrão médio calculado para a medida de altimetria do presente levantamento foi sempre inferior a $1 \mathrm{~m}$ e em poucos casos ultrapassou os $3 \mathrm{me}-$ tros (que correspondem a um erro de $1 \mathrm{mGal}$ na medida gravimétrica). As medidas que apresentaram erros superiores a esse valor foram repetidas ou omitidas do conjunto final.

Ao todo foram implantadas 548 novas estações gravimétricas que somadas àquelas existentes levantadas pelo Observatório Nacional (ON; 156) e pela Uni-

Tabela 3 - RN`s do IBGE, utilizadas no levantamento altimétrico por barometria.

\begin{tabular}{c|c|c|c|c}
\hline LON & LAT & ALT & RN & Local \\
\hline-34.8597 & -7.1269 & 47.5934 & $396-\mathrm{A}$ & Joao Pessoa -Igreja Matriz \\
\hline-35.5450 & -6.9500 & 133.9636 & $437-\mathrm{S}$ & Alagoinha- Igreja Principal \\
\hline-35.1253 & -6.8383 & 35.8048 & $450-\mathrm{U}$ & Mamanguape- Igreja Matriz \\
\hline-35.0769 & -6.8064 & 11.9047 & $450-\mathrm{Z}$ & Rio Tinto -Igreja \\
\hline-34.8094 & -7.4706 & 3.7267 & $2444-\mathrm{E}$ & Pirpirituba- Igreja \\
\hline-35.4908 & -6.8536 & 97.5891 & $2463-\mathrm{P}$ & Guarabira -Igreja \\
\hline-35.4881 & -6.8583 & 87.0436 & $2463-\mathrm{R}$ & Guarabira- Estaçao Ferroviária \\
\hline-35.3786 & -6.8525 & 57.6659 & $2463-\mathrm{X}$ & Araçaji- Igreja \\
\hline-35.2475 & -6.8286 & 81.9124 & $2464-\mathrm{H}$ & Itapororoca- Igreja \\
\hline-35.4439 & -6.6878 & 331.3543 & $2465-\mathrm{F}$ & Serra da Raiz- Igreja \\
\hline-35.3789 & -6.6736 & 154.9029 & $2465-\mathrm{H}$ & Lagoa de Dentro-Igreja \\
\hline-35.2917 & -6.6153 & 199.5597 & $2465-\mathrm{S}$ & Jacaraú -Escola Sen. Rui Carneiro \\
\hline-35.2378 & -6.6950 & 57.0471 & $2465-\mathrm{X}$ & Ponte sobre o Rio Camaratuba \\
\hline-35.0511 & -6.6008 & 14.9454 & $2466-\mathrm{H}$ & Mataraca -Igreja Principal \\
\hline-7.0606 & 143.5876 & $2467-\mathrm{U}$ & Mari- Igreja Principal \\
\hline
\end{tabular}


versidade Federal do Rio Grande do Norte (UFRN; 296) constituem uma base de dados com 1.000 estações (vide Fig. 7). O conjunto de medidas gravimétricas se distribui numa área total de cerca $650 \mathrm{~km}^{2}$, com espaçamentos da ordem de $5 \mathrm{~km}$ nas áreas mais afastadas e de $250 \mathrm{~m}$ sobre o corpo de Itapororoca. Em correspondência a esse corpo onde se efetuou o detalhamento foram implantadas mais de 200 estações.

O cálculo das anomalias de gravidade em cada ponto de medida levou em consideração as medidas de "g", da altitude, do efeito de maré sólida, e o valor teórico da gravidade calculado para o geóide de referência.

A gravidade de referência é definida pela chamada Fórmula Internacional da Gravidade de 1967 (equação 1),

$\gamma(\varphi)=978031.85\left(1+5.278895 \cdot 10^{-3} \operatorname{sen}^{2} \varphi+2.3462 \cdot 10^{-5}\right.$ $\left.\operatorname{sen}^{4} \varphi\right) \mathrm{mGal}$

onde $\varphi$ é a latitude geodésica da estação gravimétrica.

A anomalia Bouguer é calculada pela expressão (equação 2):

$\Delta \mathrm{g}_{\mathrm{B}}=\mathrm{g}_{\mathrm{obs}}-\gamma(\varphi)+0,3086-2 \pi \mathrm{G} \rho \cdot \mathrm{h}$

No presente levantamento, não foi aplicada a correção de relevo em vista da topografia pouco acidentada na região de interesse.

Na figura 7 apresenta-se a anomalia Bouguer simples (regional), após ter sido subtraído o efeito da placa de Bouguer, considerando-se $\rho=2,67 \mathrm{~g} / \mathrm{cm}^{3}$ a densidade média da topografia acima do nível do mar. Nessa figura, observa-se a distribuição das estações gravimétricas levantadas, e em destaque a área de detalhamento sobre o corpo de Itapororoca. Na figura 8 está representada a anomalia de ar livre, e na figura 9 está o mapa em detalhe de Bouguer para a área enfocada (Itapororoca e adjacências).

A configuração gravimétrica regional evidencia características da tectônica que atuou na área. Observase nitidamente o alinhamento de rios, lagoas, soerguimentos e abatimentos do Grupo Barreiras (e depósitos outros do Neógeno), todos guardando dependência de alinhamentos estruturais pretéritos, caracterizando a ocorrência de uma neo-tectônica intensa.

DETERMINAÇÃO DAS COMPONENTES REGIONAL E RESIDUAL O campo gravimétrico regional pode ser determinado de várias formas, sendo a mais utilizada a representação polinomial, cujos parâmetros são definidos por ajuste de mínimos quadrados. O grau do polinômio dependerá da geometria, dimensão e disposição espacial dos vários corpos isolados e dos segmentos crustais e litosféricos característicos de cada área.

Muitas vezes, a presença de um corpo com características 3D marcantes, pode distorcer o campo regional e introduzir componentes devidas apenas ao corpo isolado, como se observa no caso em estudo. Es-

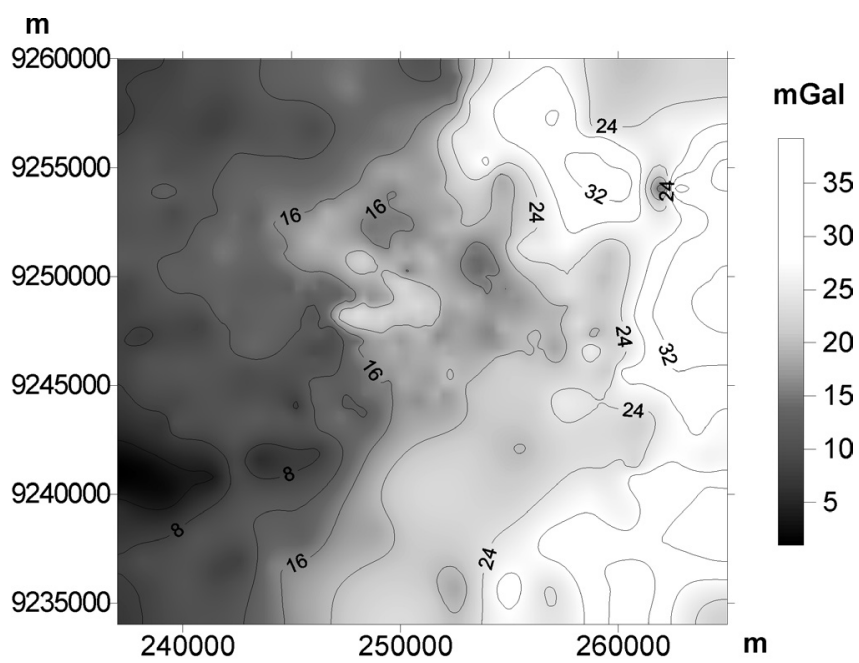

Figura 8 - Anomalia de Ar-Livre também denominada anomalia de "Faye", para a área enfocada.

m

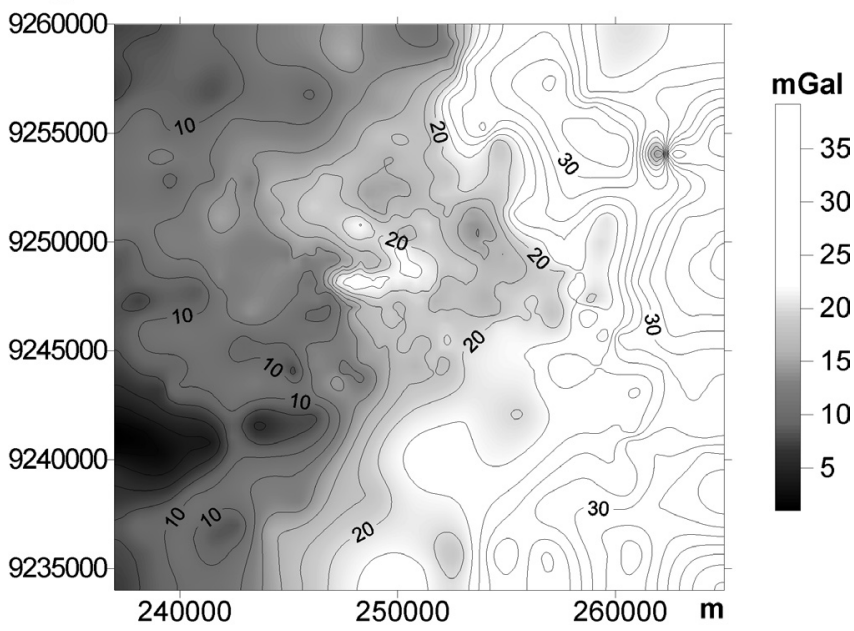

Figura 9 - Anomalia Bouguer simples, de Itapororoca e adjacências. Os pontos sinalizando as estações gravimétricas encontram-se nas figuras 7 e 11 .

sas distorções podem ser eliminadas com a utilização do método do "polinômio robusto" descrito por Beltrão et al. (1991), figura 10a.

Uma outra maneira de eliminar essas distorções é o uso do método da omissão que calcula o polinômio que melhor se ajusta aos dados após eliminar as estações que definem a anomalia. Este método, aplicado com sucesso em vários exemplos de anomalias com características de corpos com geometria 3-D, no caso em questão, selecionou como representação do campo regional a superfície interpolada por 383 pontos de um total de 428 estações na sub-área de estudo (Fig. 10b). O campo gravimétrico residual, após a extração do regional de campo está mostrado nas figuras 11 e 12 . 


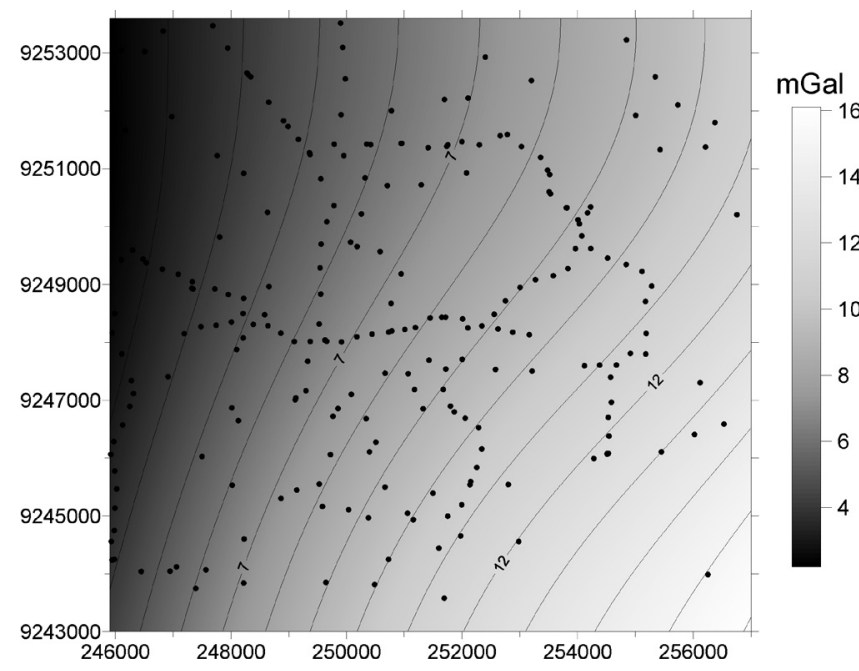

Figura 10a-Campo regional calculado pelo polinômio robusto de grau 7, de Beltrão e colaboradores (1991).

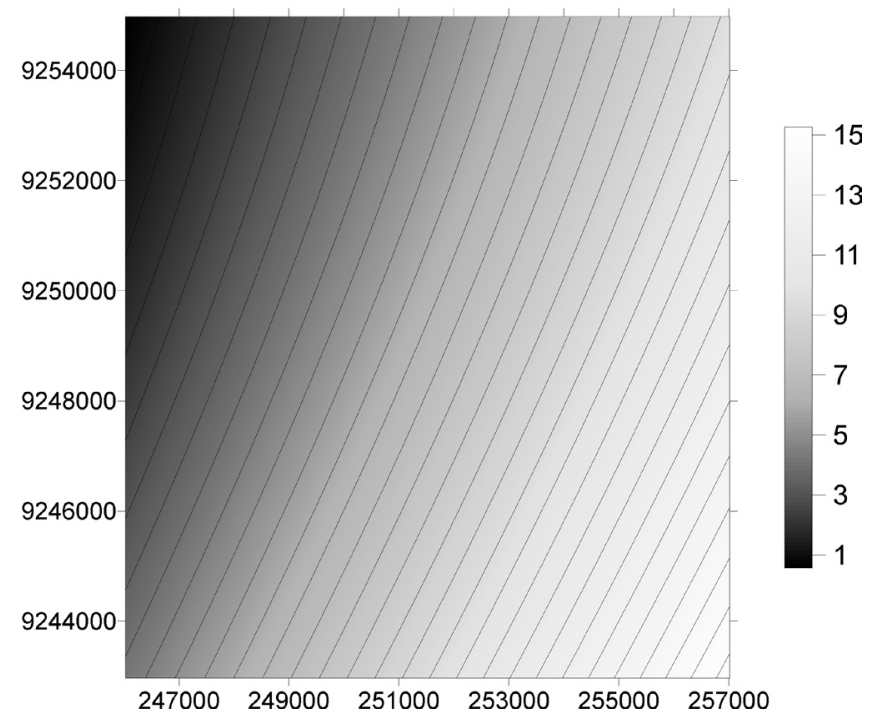

Figura 10 - Campo regional calculado método da omissão. Note-se que as maiores discrepâncias entre os dois métodos ocorrem nas bordas ou em áreas afastadas da anomalia em estudo.

Modelagem e interpretação dos dados gravimétricos Programas de cálculo numérico, que utilizam técnicas de ajuste manual ou automático para determinar a forma e o volume de um corpo geológico, se encontram disponíveis na literatura.

Uma vez que os métodos potenciais admitem múltiplas soluções, é imprescindível utilizar todos os vínculos geológicos e físicos disponíveis para obter um modelo com uma geometria próxima daquela real. A forma da anomalia permite inferir parâmetros indicativos da sua geometria e, dispondo de outros vínculos, é possível calcular sua posição e volume em sub-su-

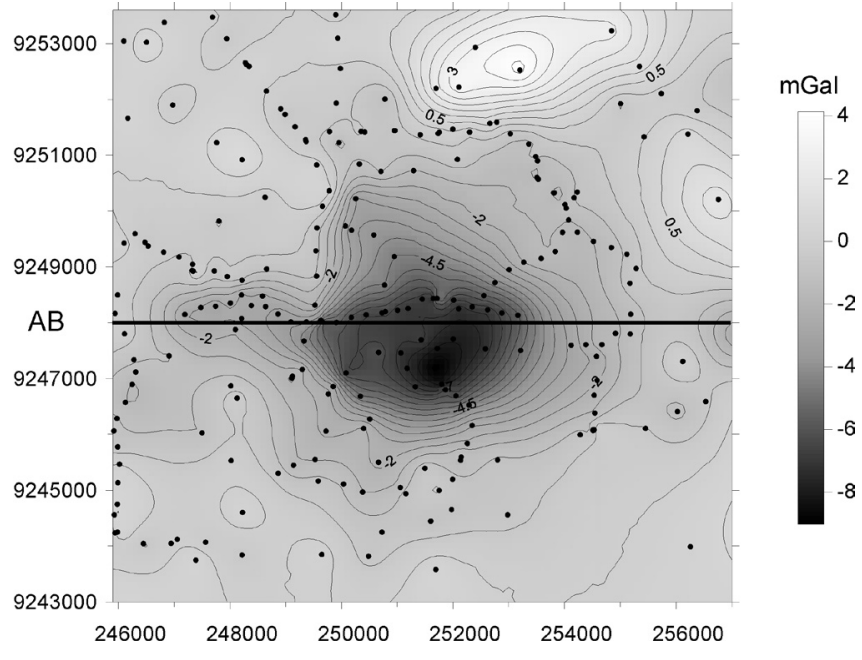

Figura 11 - Campo gravimétrico residual na região da anomalia de interesse, calculado subtraindo-se do campo anômalo observado a componente regional calculada pelo polinômio Robusto de grau 7. Nota-se que a anomalia é negativa, indicando um defeito de massa, ou seja, a presença de um corpo de menor densidade daquela da rocha encaixante. (Os pontos representam as estações gravimétricas).

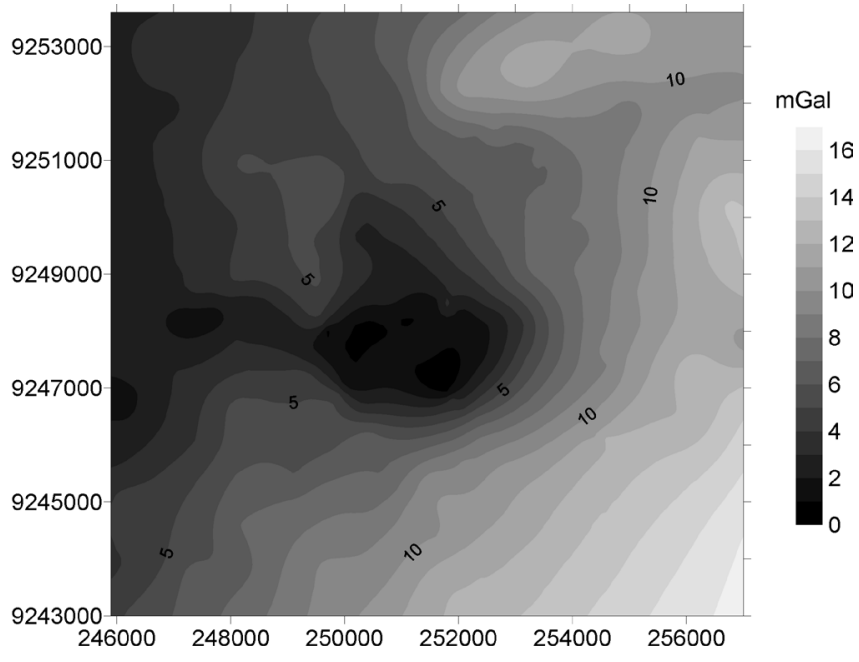

Figura 12 - Campo gravimétrico residual na região da anomalia de interesse, calculado subtraindo-se do campo anômalo observado a componente regional calculada pelo método da omissão. Nota-se a semelhança da anomalia que utilizou o outro regional.

perfície. Um parâmetro físico muito importante para a estimativa do volume do corpo é o seu contraste de densidade com a rocha encaixante.

Densidades das rochas foram medidas em laboratório, tendo sido coletadas 24 amostras das várias litologias que afloram na região de interesse (Tab. 4). As densidades utilizadas na modelagem foram a média das amostras UEPV para o corpo $\left(2,50 \mathrm{~g} / \mathrm{cm}^{3}\right)$ e a média 
Tabela 4 -Densidades em $\mathrm{g} / \mathrm{cm}^{3}$ medidas em laboratório de rochas regionais (TAP,TAM, RGN, graníticas, coberturas).

\begin{tabular}{|c|c|c|c|c|c|c|}
\hline $\begin{array}{c}\mathrm{X} \\
\text { (UTM) } \\
\end{array}$ & $\begin{array}{c}\mathrm{Y} \\
(\mathrm{UTM}) \\
\end{array}$ & Amostra & Rocha & $\begin{array}{l}\text { Formação/ } \\
\text { Localidade }\end{array}$ & $\begin{array}{c}\text { Densidade } \\
\left(\mathrm{g} / \mathrm{cm}^{3}\right)\end{array}$ & $\sigma\left(\mathrm{g} / \mathrm{cm}^{3}\right)$ \\
\hline 249640 & 9250780 & AP-CV-49 & Ortognaisse & Cariris Velhos & 2,64 & 0,04 \\
\hline 249930 & 9243320 & AP-CV-7 & Ortognaisse & Cariris Velhos & 2,62 & 0,04 \\
\hline 251210 & 9226780 & AP-CV-63 & Ortognaisse & Cariris Velhos & 2,66 & 0,04 \\
\hline 245980 & 9244540 & AP-CV-GN-45 & Ortognaisse & Cariris Velhos & 2,57 & 0,04 \\
\hline 264190 & 9241980 & AP-MGV-1 & Metagrauvaca & São Caetano & 2,50 & 0,04 \\
\hline 225160 & 9241480 & AP-MGV-16 & Metagrauvaca & São Caetano & 2,58 & 0,04 \\
\hline 259290 & 9231800 & AP-SC-54 & Metagrauvaca & São Caetano & 2,53 & 0,04 \\
\hline 258160 & 9228170 & TAM-56 & gnaisse & Terreno Alto Moxotó & 2,67 & 0,04 \\
\hline 252210 & 9256810 & LP-GR-34 & Granito & Lineamento Patos & 2,99 & 0,04 \\
\hline 266600 & 9245130 & AP-GR-M1 & Granito & Mamanguape & 2,60 & 0,04 \\
\hline 259610 & 9245320 & AP-GR-M3 & Granito & Mamanguape & 2,66 & 0,04 \\
\hline 233270 & 9230270 & AP-GR-70 & Granito & Mamanguape & 2,76 & 0,04 \\
\hline 243030 & 9243650 & AP-SL-10 & Granito & Santa Lúcia & 2,61 & 0,04 \\
\hline 257720 & 9248570 & AP-GR-ALA-27 & Granito & As Alagoas & 2,62 & 0,04 \\
\hline 226390 & 9347660 & AP-GR-ESP-18 & Granito & Esperança & 2,64 & 0,04 \\
\hline 233710 & 9241590 & AP-GR-AR-14 & Granito & Araçaji & 2,64 & 0,04 \\
\hline 227710 & 9267120 & RN-GR-SR-22 & Granito & Serra da Raiz & 2,69 & 0,04 \\
\hline 255450 & 9251350 & UEPVb & UEPVb & Destilaria Xuá & 2,58 & 0,04 \\
\hline 249880 & 9248030 & UEPVo (?) & UEPVo? & Riacho timbó & 2,65 & 0,04 \\
\hline 255450 & 9251350 & UEPVa & UEPVa & Destilaria Xuá & 2,47 & 0,04 \\
\hline 255450 & 9251350 & UEPVa & UEPVa & Destilaria Xuá & 2,43 & 0,04 \\
\hline 249880 & 9248030 & UEPVo (?) & UEPVo? & Riacho Timbó & 2,81 & 0,04 \\
\hline 249880 & 9248030 & UEPVo (?) & UEPVo? & Riacho Timbó & 2,70 & 0,04 \\
\hline 255455 & 9251351 & UEPVd & UEPVd & Mendonça & 2,53 & 0,04 \\
\hline
\end{tabular}

daquelas representativas da encaixante nas proximidades do corpo $\left(2,67 \mathrm{~g} / \mathrm{cm}^{3}\right)$. Note-se que, embora classificados como UEPV, as amostras coletadas no Riacho Timbó não parecem corresponder a esta unidade, tendo pois sido ignoradas.
Modelos de corpos que reproduzem as anomalias observadas podem ser obtidos projetando sobre perfis a anomalia calculada para um polígono, ou sobre uma superfície aquela produzida por um sólido de forma arbitrária. No primeiro caso a modelagem é referida 
como 2D ou 2,5D, e é mais apropriada para corpos longitudinais, ou seja, com uma dimensão espacial muito maior do que as outras: é o caso de falhas, contatos, suturas entre outros. Anomalias simétricas e bem localizadas, como no caso em estudo, são características de corpos com geometria tridimensional (3D) como por exemplo intrusões, plugs, diápiros, entre outros. É comum, antes de se modelar um corpo com geometria 3D, traçar alguns perfis para obter sua forma aproximada numa seção vertical, fornecendo assim as condições iniciais de ajuste mais próximas do modelo esperado para acelerar o processo de ajuste.

\section{MODELAGEM DO CORPO COM GEOMETRIA 2,5}

$D$ Na modelagem com geometria 2,5 D utilizou-se o programa numérico GravMag, elaborado pelo British Geological Survey (Pedley et al. 1997).Esse programa permite ajustar a forma de uma secção vertical do corpo movendo os vértices do polígono que o representa. Para diferentes litologias é possível ajustar vários polígonos, cada um representativo de uma litologia tendo um valor de densidade característico da litologia ou, como no presente caso, medido em laboratório.

Na figura 13 observa-se, como exemplo o modelo obtido para o perfil AB. Essa modelagem é utilizada somente como um ajuste para a obtenção de parâmetros iniciais a serem utilizados na modelagem $3 \mathrm{D}$, Considerou-se apenas uma litologia, tendo um contraste de densidade com a rocha encaixante de $0,17 \mathrm{~g} /$ $\mathrm{cm}^{3}$. Para essas condições, observa-se que na posição de mínimo de anomalia deste perfil a profundidade do corpo resulta cerca de $8.500 \mathrm{~m}$ e o corpo apresenta um formato bi-modal sugerindo dois dutos. Observe-se também que o perfil não atravessa o centro de mínimo da anomalia do corpo.

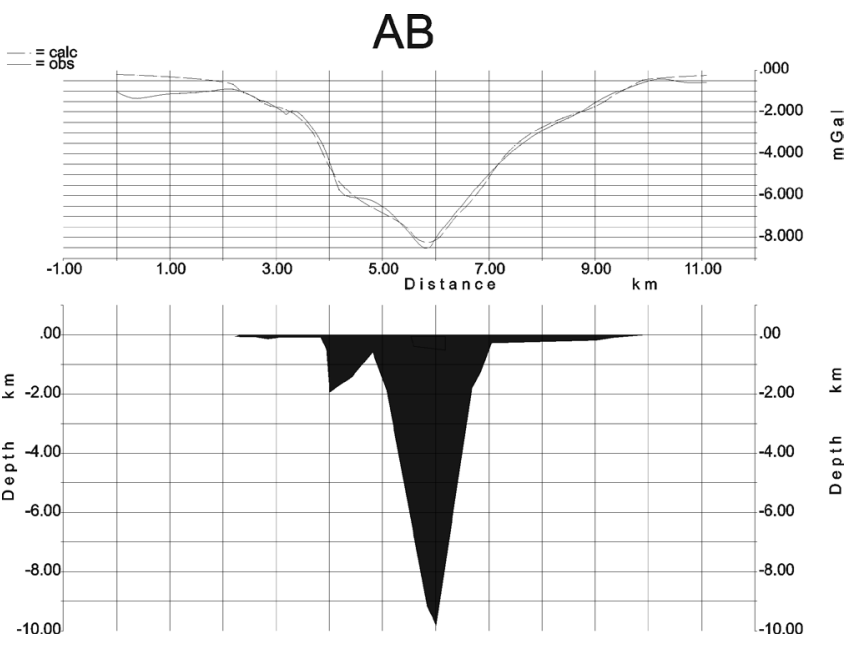

Figura 13 - Modelagem gravimétrica preliminar do perfil AB, traçado na Fig. 11, com a utilização do programa GRAVMAG (Pedley et al., 1997). Seu resultado é tomado como ponto de partida para a modelagem $3 D$.
Pequenas variações nos valores do contraste de densidade não permitem obter grandes variações do modelo, a não ser relativamente à profundidade, uma vez que esse parâmetro influi principalmente na amplitude da anomalia; os vínculos geológicos, com base nas observações de superfície, definiram a forma resultante.

\section{MODELAGEM DO CORPO COM GEOMETRIA 3D}

A modelagem para uma geometria $3 \mathrm{D}$ foi obtida utilizando-se o programa de cálculo IGMAS (Götze \& Lahmeyer 1988). Nesse programa são traçados vários perfis paralelos, cobrindo a anomalia, e sobre os quais é feito o ajuste de acordo com os vínculos existentes. Ao se modificar qualquer parâmetro em cada perfil, os demais perfis paralelos são ajustados automaticamente, seja quanto à forma dos polígonos (variando a posição dos nós) ou no contraste de densidade entre as duas litologias adjacentes (corpo e encaixante). No modelo apresentado, as máximas profundidades obtidas não ultrapassam $1800 \mathrm{~m}$, sendo o volume total do corpo de aproximadamente $23 \mathrm{~km}^{3}$ considerando-se o contraste de densidade $\Delta \rho=-0,170 \mathrm{~g} / \mathrm{cm} 3$ relativamente à rocha encaixante (vide Fig. 14a, 14b e 14c). O corpo resultante tem geometria irregular, apresentando duas raízes ou dutos, análogos àqueles modelados com geometria 2.5 D. E, portanto, a distribuição da massa tende para uma direção aproximadamente $\mathrm{WNW}$, em dois depocentros.

A análise estatística ao longo do perfil em correspondência à latitude de $9248 \mathrm{~km}$ apresenta um desvio padrão de 0,12 e um coeficiente de correlação de 0,99 . Esses valores sugerem que o modelo obtido representa adequadamente a forma do corpo em profundidade, cuja manifestação gravimétrica em superfície pouco

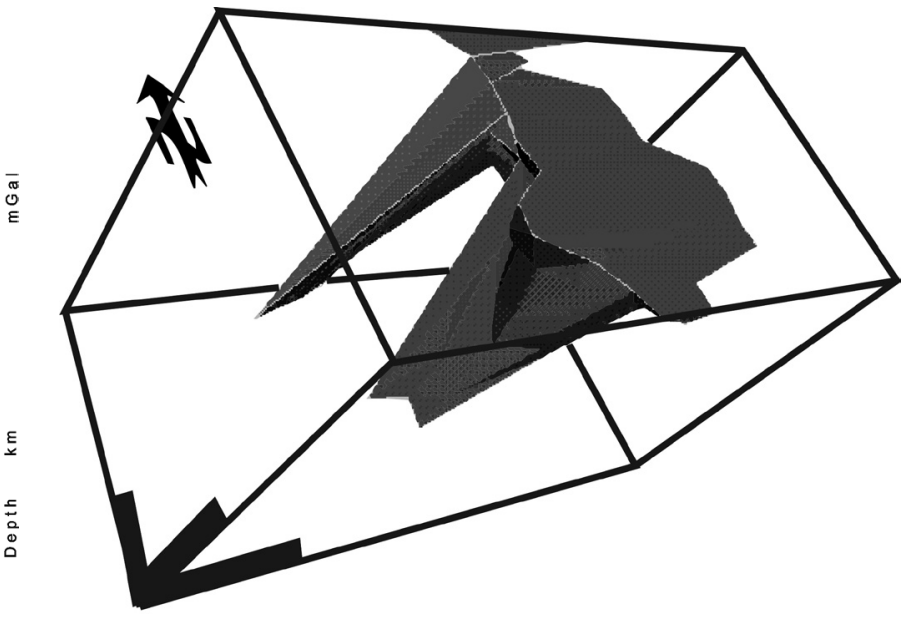

Figura $14 a$ - Modelagem com geometria $3 D$ da anomalia de Itapororoca. O programa IGMAS de ajuste (Göetze \& Lahmeyer, 1988), permite calcular a geometria e volume do corpo, que resultou em aproximadamente $23,0 \mathrm{~km}^{3}$ e com duas raizes (uma principal e outra secundária, prováveis condutos principais de injeção do magma). 


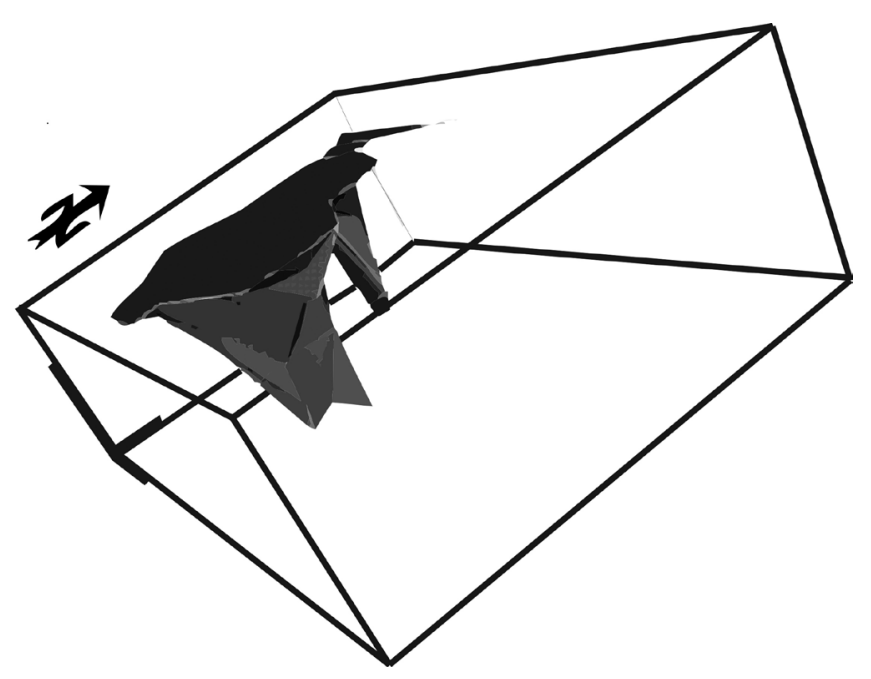

Figura $14 b$ - Modelagem com geometria $3 D$ da anomalia de Itapororoca vista de outro ângulo. Nesta também se observam claramente os dois dutos.

difere daquela calculada.

O contraste de densidade negativo, do corpo relativamente à encaixante, indica a existência de material de baixa densidade, fraturado, hidrotermalizado e/ou alterado. A intensa magnetização manifestada jus-

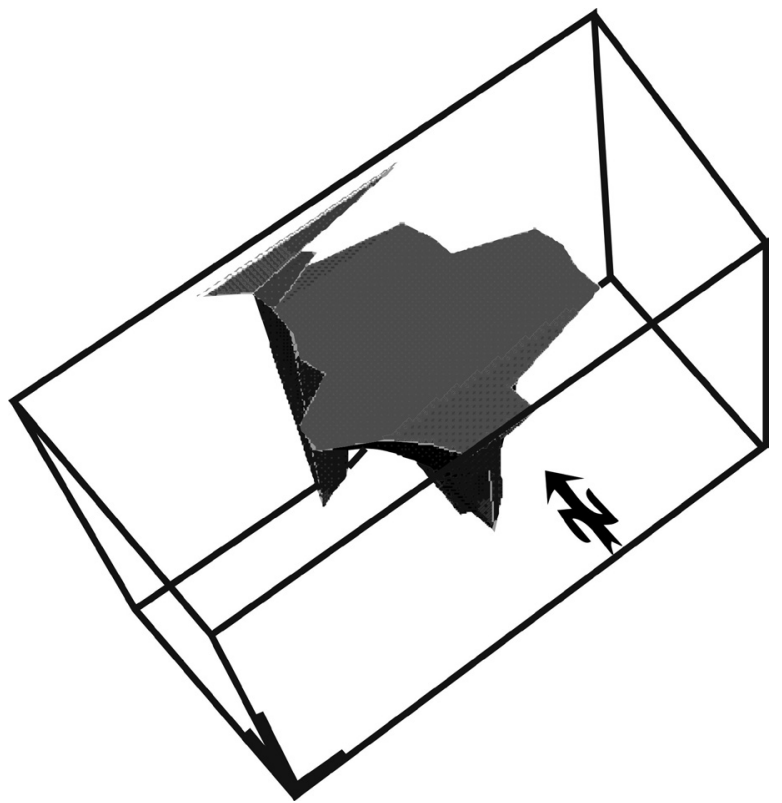

Figura 14c - Modelagem com geometria $3 D$ da anomalia de Itapororoca vista de cima. Neste caso os dutos não se distinguem tão bem como nas anteriores, mas se pode observar a reprodução da modelagem em superficie, relativamente à forma da anomalia.

tifica o alto teor de magnetita observado em superfície em correspondência ao corpo.

\section{Referências}

Alheiros M.M. \& Lima Filho M.F. 1991. A Formação Barreiras. Estudos Geológicos (UFPE), Série B, Estudos e Pesquisas, 10:77-88.

Almeida C.N., Guimarães Silva Filho A.F. 1997. Sm-Nd isotope geochemistry and $\mathrm{U}-\mathrm{Pb}$ gechronological data of the Campina Grande Complex, Paraíba State, NE Brazil. In: SBG/Núcleo Nordeste, Simp. de Geol. do Nordeste, 17, Fortaleza, Resumos Expandidos, Boletim n. 15, p. 3-6.

Amaro V.E. 1998. Análise conjunta de dados geológicos, geofísicos e de sensoriamento remoto do setor extremo nordeste da Província Borborema, Nordeste do Brasil, com ênfase nas zonas de cisalhamento dúcteis neoproterozóicas. Tese de Doutoramento, Instituto de Geociências da Universidade de São Paulo, 393p.

Archanjo C.J \& Fetter A.H. 2004. Emplacement setting of the granite sheeted pluton of Esperança (Brasiliano Orogen, Northeastern Brazil). Precambrian Research, 135:193-215.

Barbosa A.J., Braga A.P.G., Bezerra M.A. 1974. Projeto Leste da Paraíba e Rio Grande do Norte. Relatório Final Integrado, folhas SB.25-V-C e SB. 25- A. $1 / 250000$ - CPRM-Recife, 4 vol.

Barbosa A.J., Souza E. M., Lima Filho M.F., Neumann V.H. 2003. Estratigrafia da Bacia Paraíba, NE Brasil: uma nova proposta a partir da Estratigrafia de Seqüências.
Congresso Pesquisa \& Desenvolvimento em Petróleo e Gás da UFPE, 1, e Reunião de Avaliação do PRH/ANP/ MCT, 3, Recife, Boletim de Trabalhos, p. 100-108.

Barbosa J.A., Souza E.M., Lima Filho M.F., Neumann V.H. 2003. A estratigrafia da Bacia Paraíba: uma reconsideração. Estudos Geológicos, 13:89-108.

Barbosa J.A ., Souza E.M., Lima Filho M.F., Neumann V.H. 2002 . Estratigrafia da Bacia Paraíba: uma nova proposta a partir da estratigrafia de seqüências. In: Congresso Pesquisa \& Desenvolvimento, 1, Reunião de Avaliação dos Programas de Formação de Recursos Humanos (PRH/ ANP/ MCT) para o setor de petróleo e gás, 3, Boletim de Trabalhos, p. 100-108.

Beltrão J.F., Silva J.B.C., Costa J.C. 1991. Robust polynomial fitting method for regional gravity estimation. Geophysics, 56:80-89.

Brito Neves B.B., Araújo Filho J.C., Bezerra F.H., Correia A.C.B., Barreto A.M. 2005. A Unidade Pedoestratigráfica Engenho Novo no Leste da Paraíba. In: SBG/Núcleos Nordeste e Bahia-Sergipe, Simpósio de Geologia do Nordeste, 21, Resumos Espandidos, vol. 19, p. 246249.

Brito Neves B.B., Campos Neto M.C., Van Schmus W.R., Santos E.J. 2001a. O Sistema Pajeú-Paraíba e o Maciço São José do Campestre no Leste da Borborema. Revista 
Bras. Geoc., 31:173-184.

Brito Neves B.B., Campos Neto M.C., Van Schmus W.R., Fernandes T.M. 2001b. O Terreno Alto Moxotó no Leste da Paraíba (Maciço Caldas Brandão). Revista Bras. Geoc., 31:185-194.

Dantas E.L. 1997. Geocronologia U-Pb e Sm-Nd de Terrenos arqueanos e Paleoproterozóicos do Maciço Caldas Brandão, NE Brazil. Rio Claro, Tese de Doutoramento, IGCE/UNESP, 208p.

Dantas E.L., Hackspacher P.C., Brito Neves B.B., Van Schmus W.R. 2005. The Rio Grande do Norte terrane: a forgotten Atlántica fragment in Rodinia arrangement. In: Gondwana 12 "Geological and Biological Heritage of Gondwanaland”, Mendonça-Argentina, Abstracts, p. 129.

Dantas E.L, Hackspacher P.C., Van Schmus W.R., Brito Neves B.B. 1998. Archean accretion in the S. José do Campestre massif, Borborema Province, Northeast Brazil. Revista Bras. Geoc., 28:221-228.

Feitosa E.C., Feitosa F.C., Lira H.M.P. 2002. Relações estratigráficas e estruturais entre a Bacia Potiguar e a Bacia Costeira PE/PB - uma hipótese de trabalho. In: ABAS, Congresso Brasileiro de Águas Subterrâneas, 12, Florianópolis-SC, Anais (em CD).

Götze H.J. \& Lahmeyer B. 1988. Application of three - dimensional interactive modeling in gravity and magnetics. Geophysics, 53(8):1096-1108.

Guimarães I.P., Almeida C.N., Vieira K.J. 2003. Magmatismo Brasiliano no Maciço São José do Campestre: O Complexo Solânea. In: SBG, Simp. Geol. Nordeste, 20, Anais, Boletim 18, p. 64.

Howell H.D. 1995. Principles of Terrane Analysis. New Application for Global Tectonics. New York, Chapaman \& Hall, 245p.

Jardim de Sá E.F., Trindade R.I.F., Hollanda M.H.B.M., Araújo J.M.M., Galindo A.C., Amaro V.E., Souza Z.S., Vigneresse J.L., Lardeaux J.M. 1999. Brasiliano Syntectonic Alkaline Granites Emplaced in a Strike Slip/ Extensional Setting (Eastern Seridó, Brazil). Anais da Acad. Bras. Ciên., 71:17-28

Longman I.M. 1959. Formulas for computing the tidal accelerations due to the Moon and the Sun. J. Geophys. Res., 64:2351-2355.

Mabessone J.M. \& Castro C. 1975. Desenvolvimento geomorfológico do Nordeste Brasileiro. Núcleo Nordeste da SBG., Boletim 3, p. 5-36.

Mabessone J.M. \& Silva J.C. 1991. Aspectos Geomorfológicos. Estudos Geológicos (UFPE), Série B, Estudos e Pesquisas, 10:117-132.

McLintock D., Deren E.J., Krakiwsky E.J. 1994. Environment sensitive: DGPS and barometry for seismic surveys. GPS World, 6:20-26

Menezes M.R., Moraes Neto J.M., Szatmari P, York D. 2003.
Relação cronológica entre o vulcanismo Macau e a Formação Serra do Martins com base em datação Ar-Ar do plug basáltico Serrote Preto (RN, Nordeste do Brasil). In: SBG, Simpósio Nacional de Estudos Tectonicos, 9, Búzios/RJ, Resumos Expandidos, p. 246-247.

Moraes Neto J.M. 1999. As coberturas sedimentares terciárias do interior da Paraíba e do Rio Grande do norte e a gênese da antéclise da Borborema. Dissertação de Mestrado, Escola de Minas de Ouro Preto, 170 p.

Moraes Neto J.M \& Alkmim F.F. 1998. As formações Serra do Martins e Barreiras no Nordeste da Paraíba: implicações na idade do soerguimento do Planalto da Borborema. In: SBG, Cong. Bras. Geologia, Belo Horizonte, 40, Boletim de Resumos, p.72.

Pedley R.C., Busby J.P., Dabek Z.K. 1997. GRAVMAG user manual: interactive $2.5 \mathrm{D}$ gravity and magnetic modeling. Technical report British Geological K/93/26/R, Keyworth, 73 p.

Radhakrishna Murhy I.V. \& Swamy K.V. 1996. Gravity anomalies of a vertical cylinder of polygonal cross section and their inversion. Computer \& Geosciences, 22:625-630

Salvador A. 1994. International Stratigraphic guide (a guide to Stratigraphic classification, terminology and usage. $2^{\text {nd }}$ Inc. Ed., Boulder Colorado, IUGS-GSA, 214p.

Santos E.J. \& Medeiros V.C. 1999. Constraints from granitic plutonism on Proterozoic crustal growth of the Transverse Zone. Borborema Province, NE Brazil. Revista Bras. Geoc., 29:73-84.

Santos E.J., Ferreira C.A, Silva Jr. J.M.F. 2002. Geologia e Recursos Minerais do Estado da Paraíba - Texto Explicativo dos Mapas Geológico e de Recursos Minerais da Paraíba, 1/500 000. Recife- CPRM-Serviço Geológico do Brasil, Superintendência Regional do Recife, 142 p.

Talwani M. \& Ewing M. 1960. Rapid computation of gravitational attraction of three-dimensional bodies of arbitrary shape. Geophysics, 25:203-225.

Talwani M., Worzel J.L., Landisman M. 1959. Rapid gravity computation for two-dimensional bodies with application to the Mendocino submarine fracture zones. Jour. Geophys. Res., 64:49-59.

Van Schmus W.R., Brito Neves B.B. de, Williams I.S., Hackspacher P.C., Fetter A.H., Dantas E.L., Babinski M. 2003. The Seridó Group of NE Brazil, a Late-Neoproterozoic pre-to syn-collisional basin in West Gondwana: insights from SHRIMP U-Pb detrital zircon ageS and $\mathrm{Sm}-\mathrm{Nd}$ crustal residence (Tdm) ages. Precambrain Research, 127:287-327.

Manuscrito AE-043/2006 Submetido em 05 de maio de 2006 Aceito em 15 de dezembro de 2007 